International Journal of Engineering, Science and Technology

Vol. 3, No. 6, 2011, pp. 116-134
INTERNATIONAL JOURNAL OF ENGINEERING, SCIENCE AND TECHNOLOGY

WwW.ijest-ng.com

(C) 2011 Multicraft Limited. All Rights Reserved

\title{
2D study of wind forces around multiple cooling towers using computational fluid dynamics
}

\author{
H. Irtaza ${ }^{1, *}$, S. Ahmad ${ }^{2 *}$ T. Pandey ${ }^{3}$ \\ ${ }^{1}$ Department of Civil Engineering, Aligarh Muslim University, Aligarh, INDIA \\ ${ }^{2}$ Department of Civil Engineering, Aligarh Muslim University, Aligarh, INDIA \\ ${ }^{3}$ Department of Civil Engineering, Aligarh Muslim University, Aligarh, INDIA \\ "Corresponding Author: e-mail: shakeel60in@yahoo.co.in
}

\begin{abstract}
A comprehensive numerical study for the determination of wind pressure coefficients on multiple cooling towers by simulating turbulence using Reynolds Averaged Navier-Stokes Equations (RANS) models of Computational Fluid Dynamics techniques (CFD) such as, Standard $k-\varepsilon$, RNG $k-\varepsilon$, Realizable $k-\varepsilon$ and Reynolds stress method were done. The main objective of this study is to explore an effective and reliable approach for evaluation of wind force on cooling towers (in interference) using the above turbulence models. The computed results on isolated and in single interference configurations of cooling towers were compared with the wind-tunnel tests data from Indian Institute of Technology, Kanpur, India for Krishnapatnam thermal power plant in Andhra Pradesh, India, so as to ascertain the accuracy of the available turbulence model. It was found through comparison that the pressure coefficients obtained using RNG $k-\varepsilon$ turbulence model is in good agreement on the windward face of the cooling tower and has the advantage of providing rapid solutions. These results were also corroborated using recommendations of Bureau of Indian Standards Code IS: 11504-1985and IS 4998: Part 1: 1992. After validating the numerical results with the wind-tunnel data above, a pure numerical study were done on three and five cooling towers (in interference) of same geometric configuration placed staggerly at different wind incidence angle. It was found that the property of approaching wind flow mainly influences the mean pressure coefficients on the cooling towers and the incident turbulence intensity profile has a significant effect on the fluctuating wind forces. Therefore, it is necessary to correctly simulate both the incident wind velocity and turbulence intensity in CFD to accurately predict the wind force. The recommended turbulence modeling techniques and associated numerical treatments provide an effective way for the designer to access wind effects on cooling towers.
\end{abstract}

Key words: Natural Drought Cooling Towers(NDCT), CFD, Krishnapatnam thermal power plant, Wind-tunnel

DOI: http://dx.doi.org/10.4314/ijest.v3i6.10

\section{Introduction}

Natural Draught Cooling Towers (NDCT) are very common in modern day and prominent features in many thermal and nuclear power stations in view of their large size. A natural draught cooling tower is an enclosed device where hot water gets cooled under direct contact with air. These towers are small shell thickness are exceptional structures by their sheer size and sensitive to horizontal loads. The thin outer shell of the tall natural draught cooling towers can be said to be one of the greatest structural innovations of all times. The majorities of practical fluid flows are turbulent and consist of many complex flow features which may contain, among other features, recirculation zones and flow stagnation points. The types of flow encountered in the field of wind engineering are no exception (Wright et al., 2003). Due to the complexity of wind turbulence near ground (Atmospheric Boundary Layer), the past researches were mostly concentrated on either the full scale analysis of structures or wind-tunnel tests on models. This involves the use of expensive wind-tunnel tests and data recording facilities, thus, requiring significant time and effort to obtain the desired results. However during the late 1980s and due to invent of high speed computers, there had been a great deal of interest among the engineering community into a relatively new technique known as Computational Fluid Dynamics (CFD).

Invent of high speed digital computer technology had enabled the solution of flow problems, which were described mathematically by a set of coupled nonlinear partial differential equations and the appropriate boundary conditions, in a relatively short space 
of time and for a low financial cost. Initially the wind engineering community largely ignored this technique due to the need for powerful computers and the errors in early modeling techniques. Nonetheless, the rapidly falling costs of computer hardware and further advances in technology in the late 1980s enabled CFD to be applied to the complex field of wind engineering. In theory it is numerically possible to completely resolve all aspects of a fluid dynamics problem including the rapid spatial and temporal variations of turbulence in the flow using a CFD technique known as Direct Numerical Simulation (DNS). Unfortunately the DNS of practical turbulent fluid flows using the time dependent Navier-Stokes equations in their simplest form is well beyond the capabilities of present day computing power. This is due to the fact that the amount of computer processing time required is dependent on the degree of resolution of the small scale eddies. The smallest eddies in turbulent flow the so-called Kolmogorov micro scale is very small at about 0.1 to $1 \mathrm{~mm}$ for natural wind (Murakami, 1997). Therefore the numerical discretisation of an entire wind engineering flow field with a complex geometry at high Reynolds numbers is at present well beyond the capabilities of even the most powerful supercomputers available. Large Eddy Simulation (LES) provides an alternative approach in which large eddies are explicitly computed (resolved) in a time-dependent simulation using the 'filtered" Navier-Stokes equations. The rationale behind LES is that by modeling less of turbulence (and resolving more), the error introduced by turbulence modeling can be reduced. LES for high Reynolds number industrial flows requires a significant amount of computer resources. This is mainly because of the need to accurately resolve the energy-containing turbulent eddies in both space and time domains, which becomes most acute in nearwall regions where the scales to be resolved become increasingly smaller. The only economically feasible way to solve this problem is to employ statistically averaged equations which govern the mean flow equations. Turbulence models are then required to achieve closure of the averaged equations and represent the action of turbulent stresses on the mean flow. Unfortunately the mathematical models used in CFD are only able to perform as well as the physical assumptions made regarding the modelling of the turbulent component of engineering flows have proved to be major source of error in wind engineering simulations (Easom, 2000).

In the years 1999 to 2001 a new natural draft cooling tower were built at the RWE power station at Niederaussem (Germany), $200 \mathrm{~m}$ high is the highest cooling tower world-wide. For many reasons, such structures cannot be designed merely as an enlargement of smaller ones; on the contrary, it is full of innovative new design elements (Montag et al., 2004). Montag et al. (2004) presented the article with a short overview over the cooling tower and a brief description of the new cooling tower generation as well as the conceptual shape optimization concept. Special attention was focused on the structural analysis of the tower, especially the numerical modeling of the non-axisymmetric wind loading, the non-axisymmetric soil characteristics and the prestressing of the upper rim. Grebik et al. (2004) stated that from technical point of view, the construction of cooling tower with natural draught, especially realization of cooling tower walls, is very difficult. Horr et al. (2004) presented a new design strategy for large tower structures with imperfections on the basis of advanced computational plasticity and the advanced damping theories for vibration of large space structural systems. He used an artificial neural network (ANN) simulator (with back error propagating perceptron), to simulate random imperfection for nonlinear dynamic analysis of large cooling tower structures. It is also desired to search a procedure for wind pressure calculation with accuracy and reliability. He suggested using the advanced CFD analysis to design a structure with complex geometry. The purpose of this work was to present a new design method, which improves the resulting dynamic responses of large space structures with imperfections under gravity, temperature and wind loadings. Rajeshirke et al. (2004) presented the constructional approach of Natural drought cooling towers in India.

Heggade (2004) presented the works which signify that the column based hyperbolic reinforced concrete cooling towers are ecstatic in aesthetics, gigantic in nature and complex in geometry. In the past, before the computer revolution, the analysis used to be done only for membrane forces in shell elements. However, as the towers grew in stature beyond $100.0 \mathrm{~m}$ height clubbed with infamous episode of Ferry Bridge cooling tower in UK emphasized the relevance of bending analysis coupled with membrane forces. Invariably it is found that the structural criticality in NDCTs is due to the wind induced dynamic forces, which compounds the complexity of the above analysis. An iterative numerical computational algorithm to design a plate or shell element subjected to membrane and flexural forces, which are based on equilibrium consideration for the limited ultimate state of reinforcement and cracked concrete were developed by Min (2004). Equations for capacities of top and bottom reinforcements in two orthogonal directions were derived. To verify the design algorithm on the element level several experimental examples were designed. Nonlinear inelastic analyses were performed with the designed examples using the Mahmoud-Gupta's computer program to show the adequacy of the design equations. He presented a design algorithm for combined membrane and flexural forces to evolve a general design equation for reinforced concrete plates and shells, through further studies involving the performance of many more designs and analyses of different plate or shell configurations.

Babu et al. (2004) stipulated that due to the consideration of wind dynamic effects as recommended in latest international standards and codes, the forces on cooling tower shells and the associated material requirement has increased. Gomes et al. (2005) presented the wind pressure distributions by conducting experiments in wind-tunnel on models of various irregular-plan shapes. He carried experiments in a closed circuit wind-tunnel and a multi-channel pressure measurement system were used to measure mean values of loads on 1:100 scale models. The same tests were carried out on a cube shaped model as an experimental validation. Computed pressure coefficients have also been compared with wind tunnel results for normal and oblique wind incidence. A general good agreement was found for normal wind incidence whereas some differences have occurred for other directions. Huang et al. (2006) carried out a comprehensive numerical study of wind effects on the Commonwealth Advisory Aeronautical Council (CAARC) building. The CFD techniques, such as LES, RANS equations model etc., were adopted to predict wind loads on and wind flow around the building. The computed results were compared with extensive experimental data which were obtained from seven wind-tunnels. Blocken et al. (2007) carried out a numerical study of the wind speed conditions in passages between parallel buildings for a wide range of passage widths with the commercial Computational Fluid Dynamics (CFD) code 
'Fluent'. CFD validations were also performed by comparison of the numerical results with the corresponding wind tunnel measurements.

Presently, the most popular and widely used models use equations to represent a single length and velocity scale and are based on Reynolds averaging and the isotropic eddy viscosity concept. Although many of these turbulence models have been used successfully in aeronautical applications, in which fluid flow without separation may be a regular occurrence, the same is not true of wind engineering applications. Wind engineering flow fields are highly complex and are characterized by the presence of multiple recirculation zones embedded within a uni-directional flow. The addition of streamline curvature and favorable and adverse pressure gradients leads to flow fields possessing very different turbulence scales and structures. Consequently, such turbulent models have great difficulty in simulating wind engineering flow fields which are essentially transient and highly anisotropic (Easom, 2000). It is therefore apparent that one of the main obstacles to the use of CFD in wind engineering is that of turbulence modeling. Keeping in view the drawbacks associated with the turbulence modeling, the aim of this work is to study wind pressure coefficients around structures such as NDCT using CFD techniques.

In the present study various models of cooling towers were simulated at different wind incidence angle. The cooling towers in a group of three and five staggered at a spacing of two times the base diameter were simulated. The plots of pressure coefficient [wind pressure on the structure is expressed in the form of non-dimensional pressure coefficient defined as $C_{p}(t)=\left(p_{t}-p_{o}\right) /\left(\frac{1}{2} \rho U^{2}\right)$, where, $p_{o}$ is the static (ambient/atmospheric) reference pressure, $U$ the mean longitudinal wind speed at the reference height (eave height) and $\rho$ the air density. The magnitude of this minimum $\mathrm{Cp}$ is well within the current design practice. Forces required for the structural analysis of the cooling tower can be obtained by multiplying the pressure coefficient at any location with the dynamic pressure and corresponding surface area.] along the curve length were obtained at different wind incidence angle and the effects of interference of one structure on to the other were studied every single time. The RANS approach of CFD techniques were adopted for the simulation of turbulence around the cooling tower models such as Standard $k-\varepsilon$, RNG $k-\varepsilon$, Realizable $k-\varepsilon$ and Reynolds stress method. A comprehensive numerical study for the determination of wind pressure coefficients on multiple cooling towers by simulating turbulence using Reynolds Averaged Navier-Stokes Equations (RANS) models of Computational Fluid Dynamics techniques (CFD) such as, Standard $k-\varepsilon$, RNG $k-\varepsilon$, Realizable $k-\varepsilon$ and Reynolds stress method were done. The main objective of this study is to explore an effective and reliable approach for the evaluation of wind force on cooling towers (in interference) using the above turbulence models.

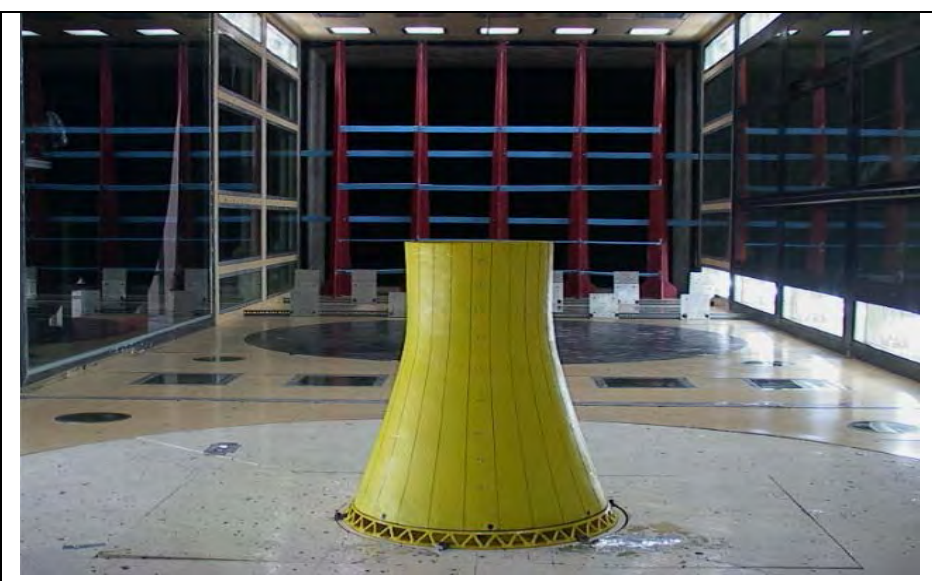

Figure 1: Krishnapatnam cooling tower (scale-1:283)

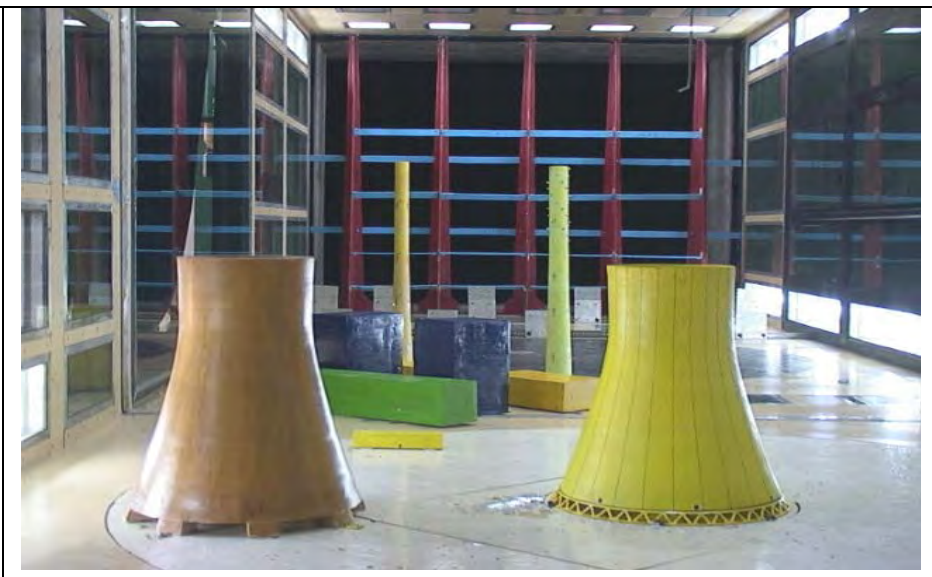

Figure 2: Krishnapatnam cooling tower (scale-1:283) - single interference

The computed results on isolated and in single interference configurations of cooling towers were compared with the windtunnel tests data from Indian Institute of Technology, Kanpur, India (2010) for Krishnapatnam thermal power plant in Andhra Pradesh, India (as shown in Figure 1 and Figure 2), so as to ascertain the accuracy of the available turbulence model. It was found through comparison that the pressure coefficients obtained using RNG $k-\varepsilon$ turbulence model is in good agreement on the windward face of the cooling tower and has the advantage of providing rapid solutions. These results were also corroborated using the recommendations of Bureau of Indian Standards Code IS: 11504-1985and IS 4998: Part 1: 1992.

After validating the numerical results with the wind-tunnel data above, a pure numerical study were done on three and five cooling towers (in interference) of the same geometric configuration placed staggerly at different wind incidence angle. It was found that the property of approaching wind flow mainly influences the mean pressure coefficients on the cooling towers and the incident turbulence intensity profile has a significant effect on the fluctuating wind forces. Therefore, it is necessary to correctly simulate both the incident wind velocity and turbulence intensity in CFD to accurately predict the wind force. The recommended turbulence 
modeling techniques and associated numerical treatments provide an effective way for the designer to access wind effects on cooling towers.

In order to assess the relative abilities of the various turbulence models used, the computational results were compared with the experimentally obtained data from wind-tunnel tests conducted on cooling towers at IIT, Kanpur, India, 2010 for Krishnapatnam thermal power plant in Andhra Pradesh (IITK, 2010). For this purpose a comparative study were carried out on an isolated case and an interference case (of two cooling towers) at different wind incidence angle. The several turbulence modeling techniques as discussed above were used to verify the experimental results and its suitability.

\section{Solution strategy}

2.1 Computational domain and mesh arrangement: The dimension of the model considered in the computational study is a 1:283 scale model of the simulated hyperbolic cooling tower of height $172.5 \mathrm{~m}$, base diameter $134.606 \mathrm{~m}$, throat diameter $76.461 \mathrm{~m}$ and top diameter $78.82 \mathrm{~m}$ installed at Krishnapatnam thermal power plant in Andhra Pradesh, India. The computational domain, coordinate definition and boundary conditions for this study are given in Figure 3. The Reynolds number involved in the simulation are in the range from $3.7 \times 10^{5}$ to $9.2 \times 10^{5}$, which are in the same range as those encountered in the wind-tunnel experiments conducted on single and interfering model at IIT, Kanpur (IITK, 2010). As shown in Figure 3, the computational domain covers 29B

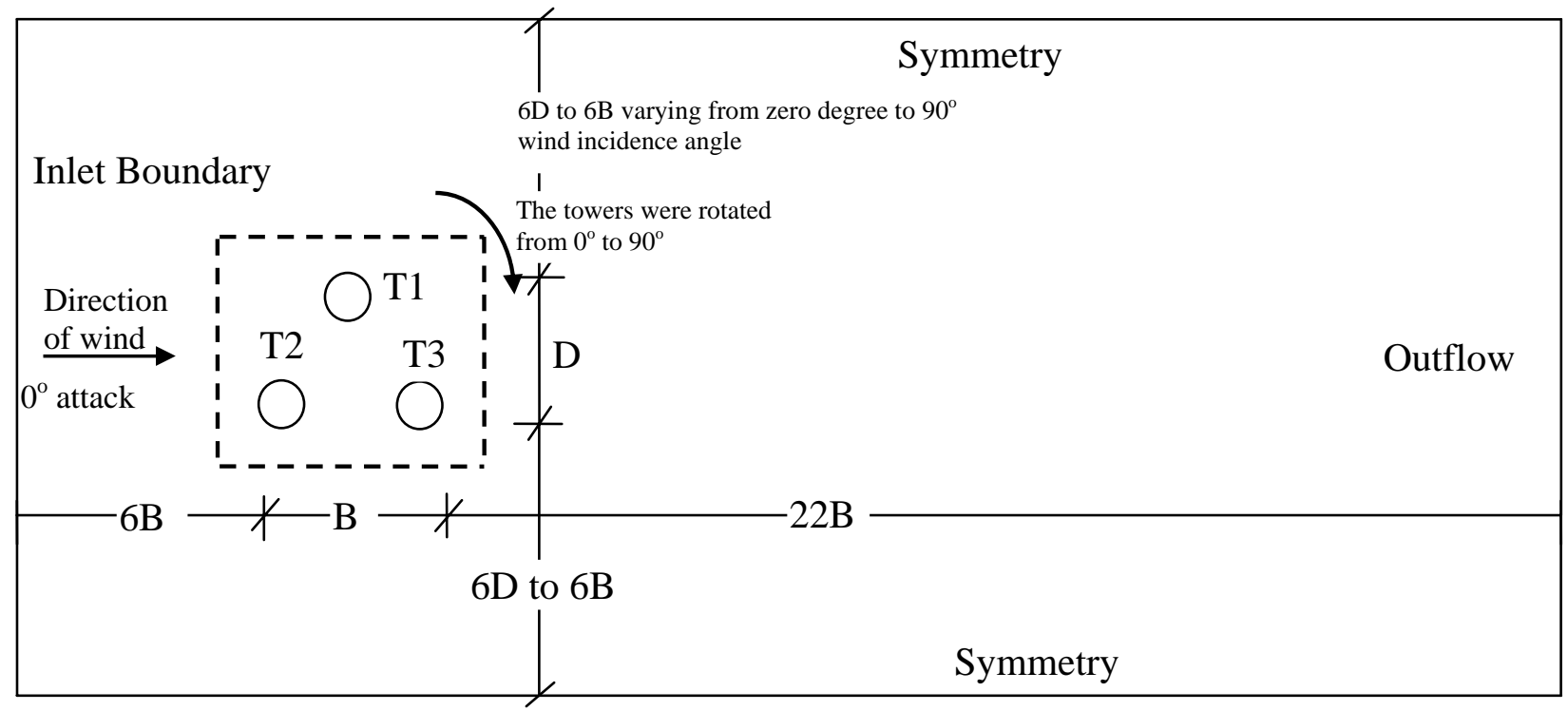

Figure 3: Computational domain and boundary conditions for three or five cooling towers placed staggerly

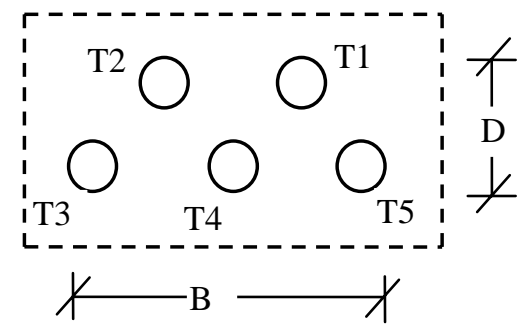

Figure 4: Arrangement of five cooling towers placed staggerly

(B is the total outer dimension of the cooling tower along the direction of flow) and 13D ( $\mathrm{D}$ is total outer dimension of the cooling tower across the direction of flow) in the lateral direction (Irtaza et al., 2009). The overall computational domain for the combination of three and five cooling towers were $21.6 \mathrm{~m} \times 4.85 \mathrm{~m}$ to $9.69 \mathrm{~m}$ and $35.4 \mathrm{~m} \times 4.85 \mathrm{~m}$ to $15.83 \mathrm{~m}$ respectively. The arrangement of five cooling towers is shown in Figure 4. The reason for such a choice is to eliminate the flow obstacle effect on the inflow and outflow boundary conditions, as discussed by Murakami (Murakami, 1998).

The mesh number must be as low as possible as we could accept for efficient computation. The number of tri-mesh varied from nearly 10,000 to 35, 0000. The level of grid refinement can have significant effect on the accuracy of the flow pattern produced by the CFD simulation. All CFD simulations should therefore be able to adequately prove that a sufficient fine mesh has been used. This is done by demonstrating that successive grid refinements do not change the flow field in any way. Therefore extensive grid independence checks were undertaken. Figure 5 and 6 shows the arrangement of mesh around isolated cooling tower and cooling 
tower with single interference. The wall unit $\left(y^{+}=\rho u_{\tau} y / \mu\right)$ in the range of 30-300 with standard wall functions have been used for all the set. The mesh near and aligned with the wall surfaces must be refined and stretched with the viscous boundary layer grid. Because of it a sufficient fine mesh (viscous boundary layer) in the neighborhood of the tower surfaces were applied and a proper coarser mesh away from it. The FLUENT (Fluent 6.3, 2006) code which is adopted in this study is based on the finite volume method, with the capacity of dealing with structured and unstructured grids in its solver. The diameter of the cooling tower at two-third height better known as stagnation height or resonant height was considered in the simulation. The cooling towers were provided centre to centre in the staggered manner at spacing of 2 times the base diameter.

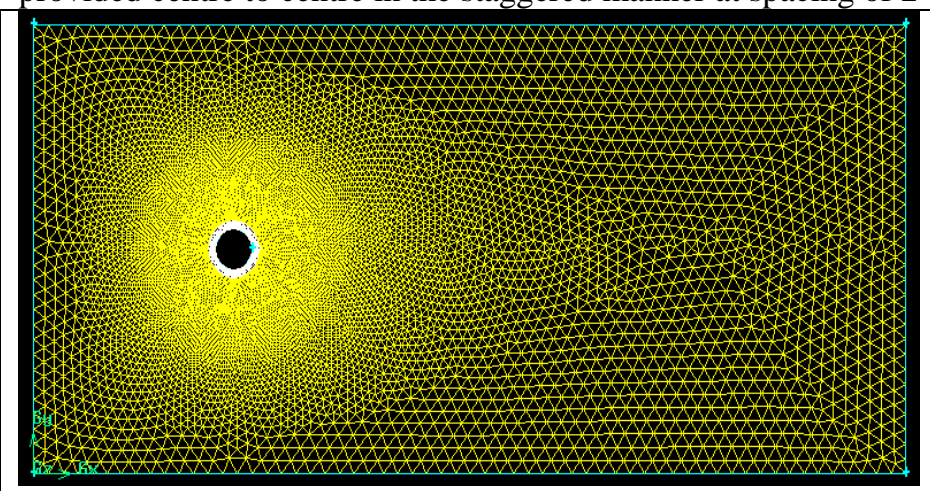

Figure 5: Triangular mesh around isolated cooling tower

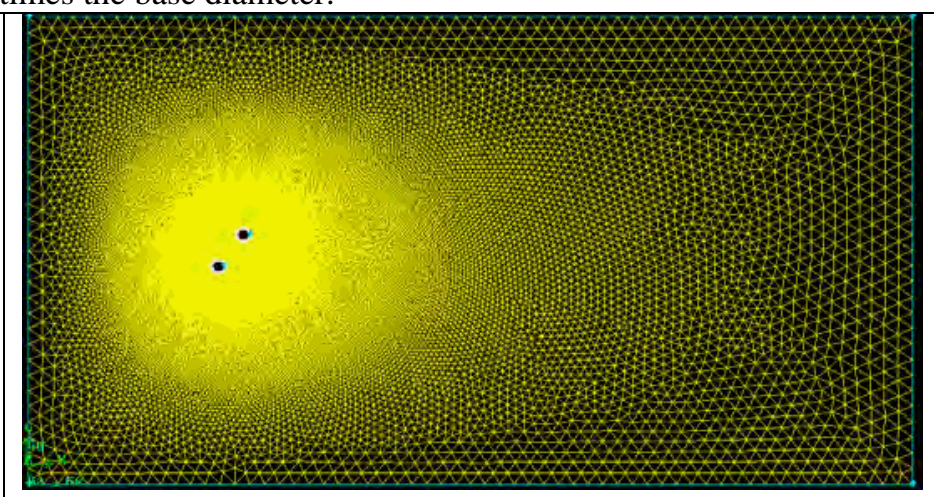

Figure 6: Triangular mesh around cooling tower with single interference

2.2 Turbulence models and numerical methods: The flow chart diagram for computation of wind loads on cooling towers is shown in Figure 7. The FLUENT code provides a variety of turbulence models to simulate turbulent flows (Fluent 6.3, 2006). Four typical turbulence models are used in the present study. They are Standard $k-\varepsilon$, RNG $k-\varepsilon$, Realizable $k-\varepsilon$ and Reynolds stress method. All these methods are also called Reynolds Average Navier-Stokes (RANS) method. As mentioned previously, these models are commonly used in simulation of wind flows around bluff body cooling towers. The transport equations and standard values of empirical constants involved in the Standard $k-\varepsilon$ RNG $k-\varepsilon$, Realizable $k-\varepsilon$ and Reynolds stress model adopted in the FLUENT code are the same as the original ones. All the discretized equations are solved in a segregated manner with the Pressure Implicit with Splitting of Operators (PISO) algorithm. The PISO involves one predictor step and two corrector steps and can be regarded as an extension of Semi-Implicit Method for Pressure-Linked Equations (SIMPLE), with a further corrector step to enhance it. All calculations were performed using discretization providing second-order accuracy (Fluent 6.3, 2006). Steady-state solution results were sought with iterations sufficient to reduce all residuals less than 0.001 (Irtaza et al.).

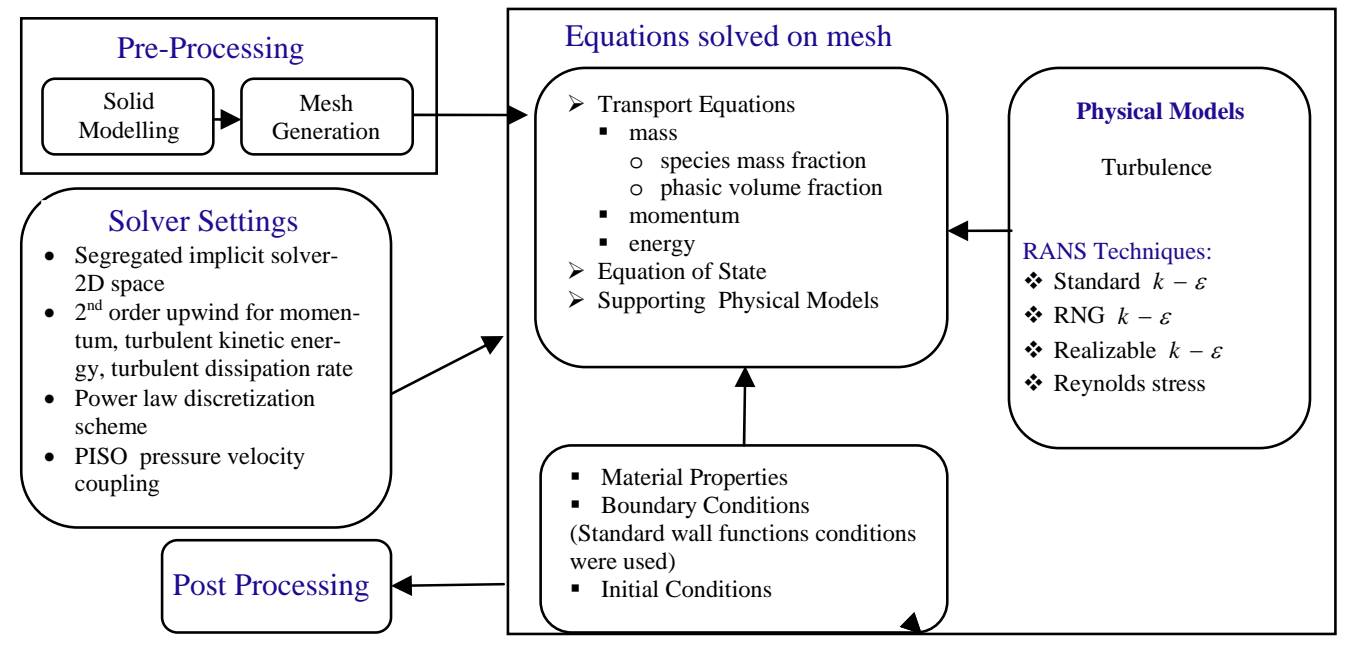

Figure 7: Flow Chart showing steps for computation through FLUENT

2.3 Boundary conditions: In order to obtain better agreement between experimental and numerical results, boundary conditions adopted in the numerical simulations should be the same as those in the experiments, especially for inflow boundary conditions. As discussed by ( $\mathrm{Li}$ et al. 1995; Li et al. 1999), turbulence intensity in the approaching flow has a significant effect on the streamwise distributions of wind-induced pressures on cooling towers, hence the turbulence intensity profile should be properly modeled for obtaining accurate simulation results (Irtaza et al. 2009). The turbulence intensity at the $2 / 3^{\text {rd }}$ height is taken as $10 \%$ equal to 
the field air turbulence. The kinetic energy of turbulence and its dissipation at the inlet section were calculated according to the following equations:

$$
\begin{aligned}
& k=\frac{3}{2}\left(U_{a v g} \times I\right)^{2} \\
& \varepsilon=C_{\mu}^{3 / 4} \frac{k^{3 / 2}}{l}
\end{aligned}
$$

Where $U_{a v g}$ is the mean velocity, $I$ is the turbulence intensity, which is interpolated from the profile at level 6, and $l$ is the turbulence integral length scale. The side boundaries of the computational domain were considered as symmetry. No-slip boundary conditions were provided on the surface of the towers.

\section{Present Study}

\subsection{Experimental study}

3.1.1 Details of wind-tunnel simulation data: In the first sets of experiments the natural drought cooling tower model for Krishnapatnam thermal power plant in Andhra Pradesh, India, were first tested under stand-alone condition (without any surrounding structures) for the simulated flow in the wind-tunnel by IIT, Kanpur, India, as shown in Figure 1. In the second sets of experiments the same cooling tower model were tested under interfering conditions (with surrounding structures, as shown in Figure 2) for the simulated flow in the wind-tunnel. The model was rotated from $0^{\circ}$ to $360^{\circ}$ in step of $15^{\circ}$ to measure wind pressure coefficients at different heights and around the periphery of the tower. The data were collected at IIT, Kanpur, India; under the simulated wind condition for isolated and single interference case and the results at $2 / 3^{\text {rd }}$ height (corresponding to level 6 as shown in Figure 7) is shown in Table 1 and Table 2. The tests were carried out in the velocity range of 20 to $30 \mathrm{~m} / \mathrm{s}$. The pressure data was analyzed to obtain the wind loading in the form of pressure coefficients on NDCT surface at various locations for stand-alone as well as interfering conditions.

Wind tunnel details:

Cross-section

Length

Contraction ratio

$: 3 \mathrm{~m} \times 2.25 \mathrm{~m}$

: $5.75 \mathrm{~m}$ (upstream part) $+3 \mathrm{~m}$ (downstream part)

Maximum wind speed $\quad: 80 \mathrm{~m} / \mathrm{s}$

Reynolds number $\quad: 5 \times 10^{6} / \mathrm{m}$

Turbulence level $\quad:<0.1 \%$

Fan

Motor rating

: 4.64 m diameter, 12 bladed

: $1000 \mathrm{~kW}$ variable speed DC motor, $450 \mathrm{RPM}$

Table 1: Pressure coefficient along the curve length on scaled Krishnapatnam NDCT for isolated case at level 6 Wind speed $=23.17 \mathrm{~m} / \mathrm{s}$, Wind incidence angle $=0^{\circ}$

\begin{tabular}{|c|c|c|c|c|c|c|c|}
\hline $\begin{array}{c}\text { Curve length } \\
(\mathbf{m})\end{array}$ & $\begin{array}{c}\text { Pressure } \\
\text { Coefficient } \\
(\mathbf{C p})\end{array}$ & $\begin{array}{c}\text { Curve length } \\
\mathbf{( m )}\end{array}$ & $\begin{array}{c}\text { Pressure } \\
\text { Coefficient } \\
(\mathbf{C p})\end{array}$ & $\begin{array}{c}\text { Curve length } \\
\mathbf{( m )}\end{array}$ & $\begin{array}{c}\text { Pressure } \\
\text { Coefficient } \\
(\mathbf{C p})\end{array}$ & $\begin{array}{c}\text { Curve length } \\
\mathbf{( m )}\end{array}$ & $\begin{array}{c}\text { Pressure } \\
\text { Coefficient } \\
(\mathbf{C p})\end{array}$ \\
\hline 0.000 & 1.314 & 0.245 & -0.028 & 0.490 & 0.027 & 0.734 & -0.283 \\
\hline 0.035 & 1.222 & 0.280 & 0.025 & 0.524 & 0.030 & 0.769 & 0.403 \\
\hline 0.070 & 0.776 & 0.315 & 0.029 & 0.559 & 0.038 & 0.804 & 1.010 \\
\hline 0.105 & 0.144 & 0.350 & 0.020 & 0.594 & 0.041 & 0.839 & 1.314 \\
\hline 0.140 & -0.511 & 0.385 & 0.036 & 0.629 & -0.142 & & \\
\hline 0.175 & -0.820 & 0.420 & 0.058 & 0.664 & -0.748 & & \\
\hline 0.210 & -0.572 & 0.455 & 0.042 & 0.699 & -0.788 & & \\
\hline
\end{tabular}


Table 2: Pressure coefficient along the curve length of tower at level 6 for single interference

\begin{tabular}{|c|c|c|c|c|c|c|c|}
\hline \multirow{2}{*}{$\begin{array}{c}\text { Curve length } \\
\text { (m) }\end{array}$} & \multicolumn{7}{|c|}{ Pressure coefficient values at different wind incidence angle (degrees) } \\
\hline & $270^{\circ}$ & $2 \mathbf{2 8 5}^{\mathbf{0}}$ & $300^{\circ}$ & $315^{\circ}$ & $330^{\circ}$ & $345^{\circ}$ & $360^{\circ}$ \\
\hline 0.000 & -0.179 & -0.717 & -0.776 & -0.330 & 0.317 & 0.975 & 1.313 \\
\hline 0.035 & -0.765 & -0.738 & -0.298 & 0.352 & 0.955 & 1.314 & 1.281 \\
\hline 0.070 & -0.720 & -0.252 & 0.371 & 0.994 & 1.289 & 1.305 & 0.819 \\
\hline 0.105 & -0.216 & 0.438 & 0.970 & 1.263 & 1.275 & 0.902 & 0.260 \\
\hline 0.140 & 0.470 & 0.977 & 1.294 & 1.265 & 0.853 & 0.248 & -0.412 \\
\hline 0.175 & 1.051 & 1.298 & 1.221 & 0.810 & 0.218 & -0.414 & -0.788 \\
\hline 0.210 & 1.323 & 1.110 & 0.766 & 0.149 & -0.442 & -0.796 & -0.650 \\
\hline 0.245 & 1.155 & 0.647 & 0.089 & -0.506 & -0.820 & -0.676 & -0.083 \\
\hline 0.280 & 0.636 & 0.043 & -0.493 & -0.843 & -0.585 & -0.083 & 0.034 \\
\hline 0.315 & -0.045 & -0.577 & -0.828 & -0.561 & -0.051 & 0.033 & 0.026 \\
\hline 0.350 & -0.611 & -0.829 & -0.503 & -0.031 & 0.044 & 0.028 & 0.028 \\
\hline 0.385 & -0.811 & -0.442 & 0.008 & 0.031 & 0.023 & 0.018 & 0.028 \\
\hline 0.420 & -0.397 & 0.009 & 0.042 & 0.033 & 0.015 & 0.026 & 0.056 \\
\hline 0.455 & 0.011 & 0.043 & 0.034 & 0.022 & 0.028 & 0.047 & 0.063 \\
\hline 0.490 & 0.048 & 0.041 & 0.030 & 0.031 & 0.057 & 0.052 & 0.043 \\
\hline 0.524 & 0.047 & 0.037 & 0.037 & 0.055 & 0.049 & 0.030 & 0.030 \\
\hline 0.559 & 0.032 & 0.046 & 0.060 & 0.041 & 0.035 & 0.028 & 0.049 \\
\hline 0.594 & 0.035 & 0.062 & 0.054 & 0.030 & 0.032 & 0.043 & 0.040 \\
\hline 0.629 & 0.060 & 0.050 & 0.040 & 0.028 & 0.051 & 0.037 & -0.113 \\
\hline 0.664 & 0.055 & 0.035 & 0.047 & 0.051 & 0.034 & -0.126 & -0.682 \\
\hline 0.699 & 0.035 & 0.046 & 0.054 & 0.025 & -0.140 & -0.710 & -0.804 \\
\hline 0.734 & 0.030 & 0.055 & 0.040 & -0.120 & -0.699 & -0.795 & -0.329 \\
\hline 0.769 & 0.050 & 0.040 & -0.123 & -0.695 & -0.795 & -0.338 & 0.355 \\
\hline 0.804 & 0.030 & -0.147 & -0.685 & -0.799 & -0.330 & 0.362 & 0.926 \\
\hline 0.839 & -0.179 & -0.717 & -0.776 & -0.330 & 0.317 & 0.975 & 1.313 \\
\hline
\end{tabular}

\subsection{Computational study}

3.2.1 Isolated case and single interference: The purpose of studying the standalone/isolated cooling tower or single interfering cooling tower is only for the validation of wind-tunnel data to that of numerical data. In this case the 2D model of NDCT were simulated using model making software Gambit 2.4 and computational analyses were done using CFD package Fluent 6.3 at twothird height (stagnation height) of the structure, at which upcoming wind flows in horizontal plane. The arrangement of meshes for the above two cases are shown in Figure 5 and Figure 6. For analytical work level 6 were considered as shown in the Figure 8, which is in close proximity of the stagnation or resonant height of the of the cooling tower. Considering the profile of the cooling tower at level 6, a 2D model of the same geometry and same scale were generated.

The simulated model were analyses using various CFD techniques such as Standard $k-\varepsilon$, RNG $k-\varepsilon$, Realizable $k-\varepsilon$ and Reynolds Stress method. The pressure coefficient values obtained were plotted along its periphery and the same were compared with the experimental data (from the wind-tunnel data of Krishnapatnam thermal power plant) of pressure coefficient at level 6. The comparisons are shown in Figure 8. The wind-tunnel results for the isolated case are given in Table 1 with the typical values plotted in Figure 8. From the Figure 9 below, it is clear that RNG $k-\varepsilon$ and Realizable $k-\varepsilon$ method is in close proximity with the experimental data.

Similarly NDCT of Krishnapatnam thermal power plant with interfering model as shown in Figure 2 were simulated at a scale of 1:283 along with existing isolated cooling tower at an angle of 54 degree (anticlockwise) with the horizontal. The simulation was carried out at different wind incidence angle from $360^{\circ}-270^{\circ}$ in step of 15 degrees. The very purpose of studying from $360^{\circ}-$ $270^{\circ}$ for the single interfering case is to capture the maximum computational data due to the presence of interfering model on the cooling towers. The mesh were generated using Gambit 2.4 and is shown in Figure 6. 
The wind tunnel results for the interfering cases are given in Table 2, and the same have been compared with the result of various CFD techniques (Figures 10-16). In each of these figures, pressure coefficients are plotted throughout its curve length. All the Figures from 10 to 16 have shown similar trends at different wind incidence angle. Out of these methods the RNG $k-\varepsilon$ and Realizable $k-\varepsilon$ method are more close to wind-tunnel experimental data. The reason for its closeness may be due to lesser production of turbulent kinetic energy, as compared to Standard $k-\varepsilon$ method, which produces higher turbulent kinetic energy.

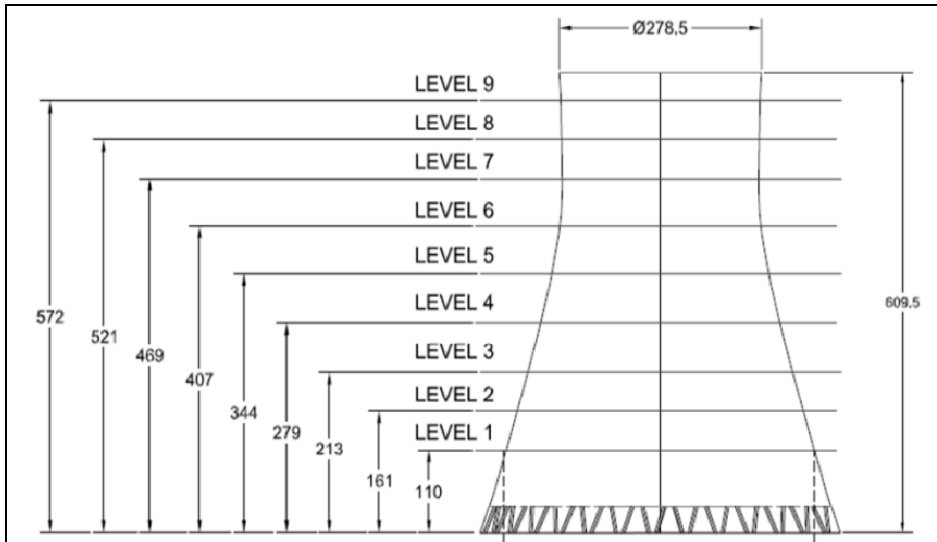

Figure 8: Sectional Elevation of Krishnapatnam cooling tower

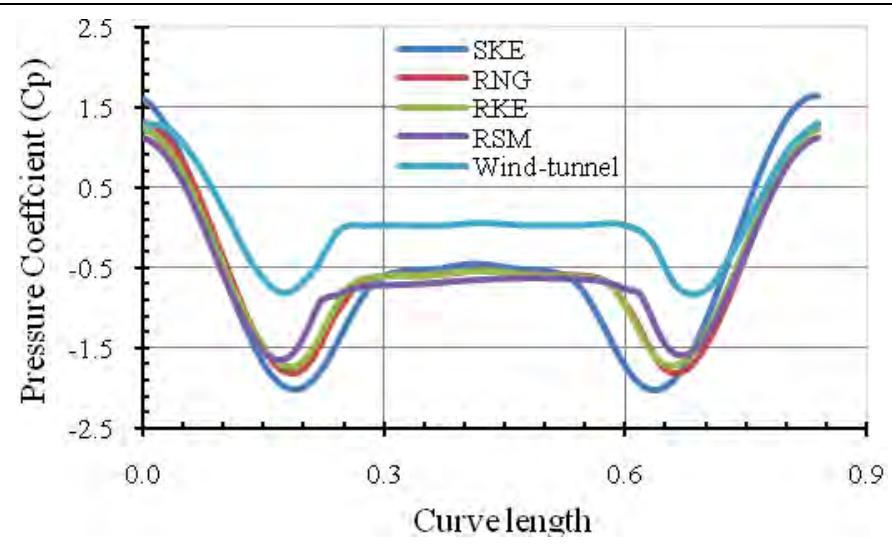

Figure 9: Pressure coefficient along the curve length of the tower at level 6

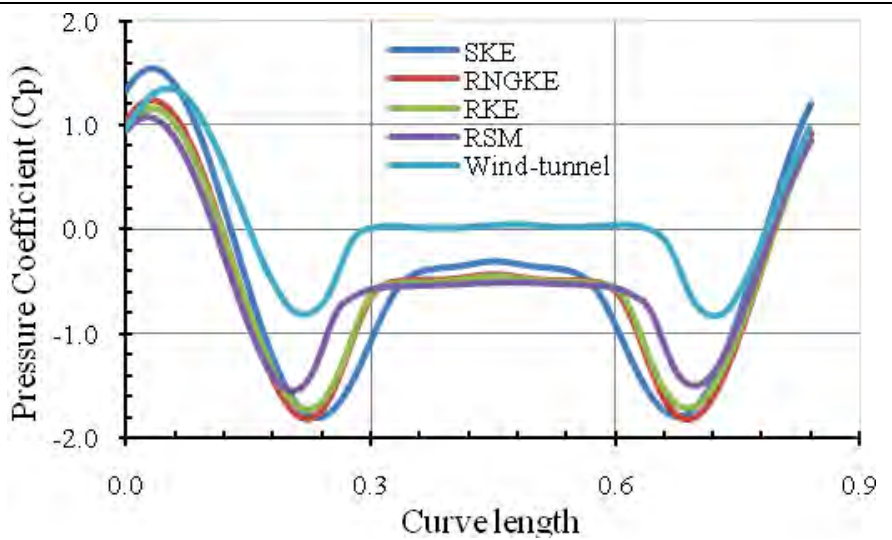

Figure 11: Pressure coefficient along the curve length of the tower for single interference when angle of incidence is $345^{\circ}$

Figure 10: Pressure coefficient along the curve length of the tower for single interference when angle of incidence is $\Xi 60^{\text {: }}$

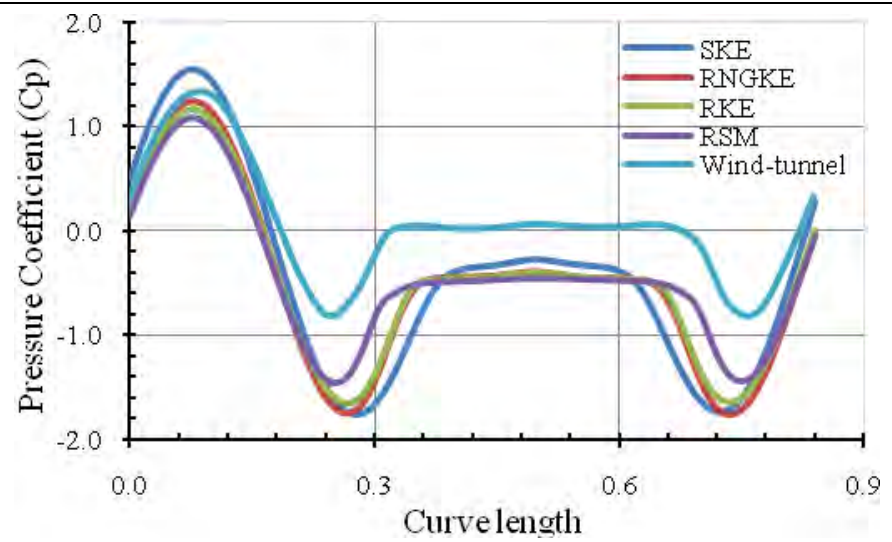

Figure 12: Pressure coefficient along the curve length of the tower for single interference when angle of incidence is $930^{\text {* }}$

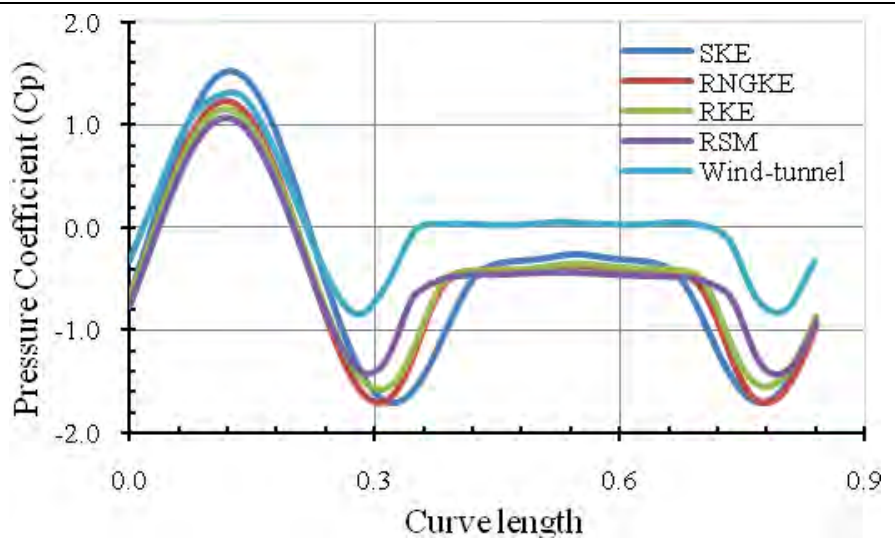

Figure 13: Pressure coefficient along the curve length of the tower for single interference when angle of incidence is $313^{2}$ 


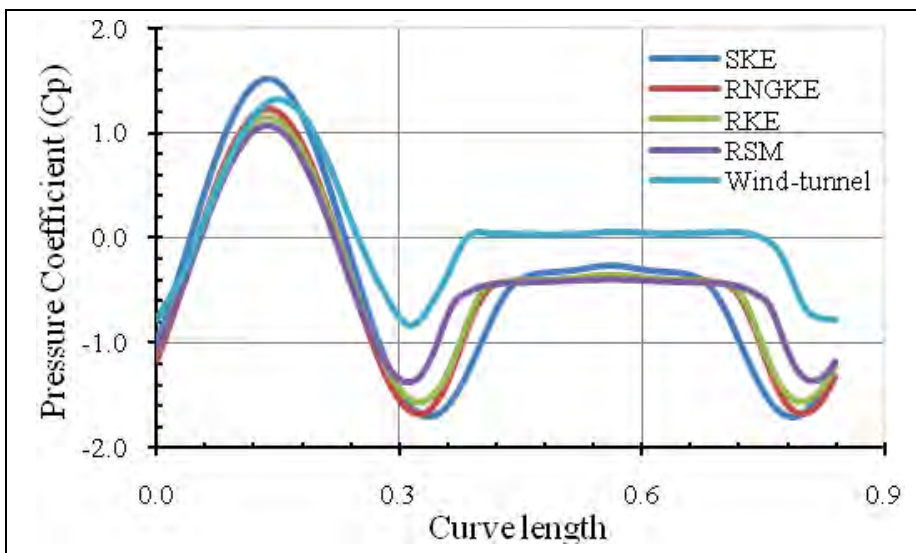

Figure 14: Pressure coefficient along the curve length of the tower for single interference when angle of incidence is $300^{\circ}$

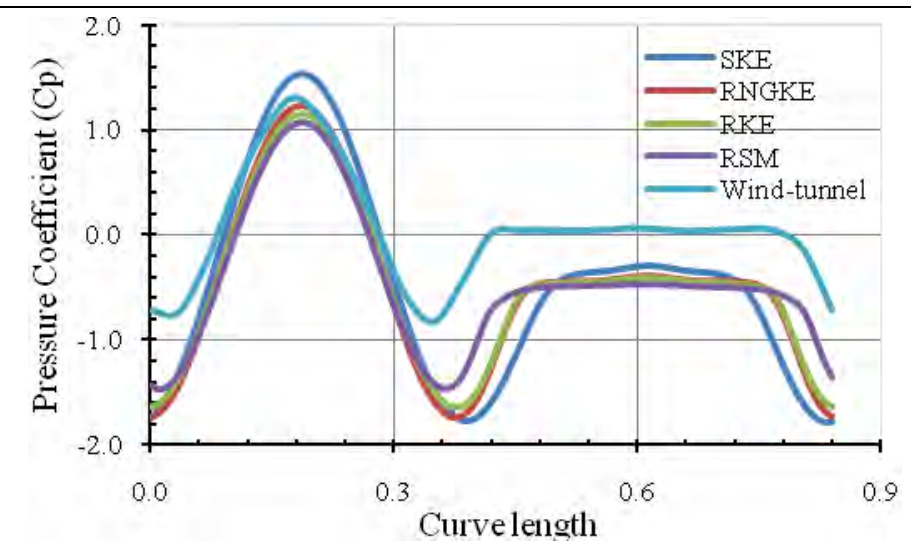

Figure 15: Pressure coefficient along the curve length of the tower for single interference when angle of incidence is $285^{\circ}$

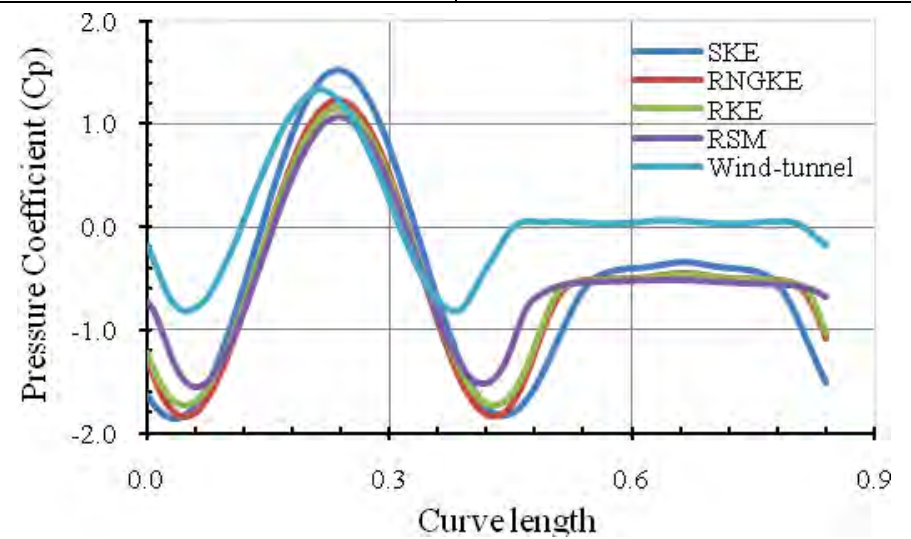

Figure 16: Pressure coefficient along the curve length of the tower for single interference when angle of incidence is $270^{*}$

3.2.2 Interference case (Three \& Five): After validating the wind-tunnel data for isolated and single interference cooling tower with the numerical results obtained from various CFD techniques, a completely numerical study were performed on three and five cooling towers placed staggerly at a spacing of two times the base diameter. The solution domain for three cooling tower were from $21.6 \mathrm{~m} \times 4.85 \mathrm{~m}$ to $9.69 \mathrm{~m}$ varying from zero degree to $90^{\circ}$ wind incidence angle, where as for five cooling towers the domain were $35.4 \mathrm{~m} \times 4.85 \mathrm{~m}$ to $15.83 \mathrm{~m}$ varying from zero degree to $90^{\circ}$ wind incidence angle. The geometric configuration of scaled cooling towers, the wind velocity, turbulence intensity, turbulent kinetic energy and its dissipation etc. have been synchronized with the experimental model for level 6. Upwind speed were simulated as per IS 11504-1985 code specification to produce a reference velocity of $67.5 \mathrm{~m} / \mathrm{s}$ at top of the cooling tower. The scaled wind speed at the reference height was in the range of $20-25 \mathrm{~m} / \mathrm{s}$, in order to get synchronizes with the modeled scale. Inlet turbulent intensity and turbulent length scale considered were 10\% and $0.3 m$ respectively. All calculations were performed using discretization providing second-order accuracy. Steady-state solution results were sought with iterations sufficient to reduce all residuals less than 0.001 . Models were simulated at different wind incidence angle from $0^{\circ}$ to $90^{\circ}$ in steps of $15^{\circ}$.

For a combination of three cooling towers placed staggerly, the pressure coefficient values were plotted along the periphery on all the three towers and the effect of interference were studied at different wind incidence angle as shown in Figure 17 to Figure 24. From Figures 19, 22, 25 it can be clearly seen that the cooling tower 3 were affected due to interference at wind incidence angle of $0^{\circ}$ and $60^{\circ}$ causing shielding effect on cooling tower 3 which led to the reduction of pressure coefficient values approximately by an amount of 50-75\%. The possible reason for this reduction is the formation of large amount of wake or negative pressure region at windward face of cooling tower 3 due to interference of cooling tower 1 when wind incidence angle was $60^{\circ}$ and due to the interference of cooling Tower 2 when wind incidence angle was $0^{\circ}$. The interference effects can also be clearly observed from $\mathrm{x}$-velocity contours at different wind incidence angle as shown in Figures 26-29. 


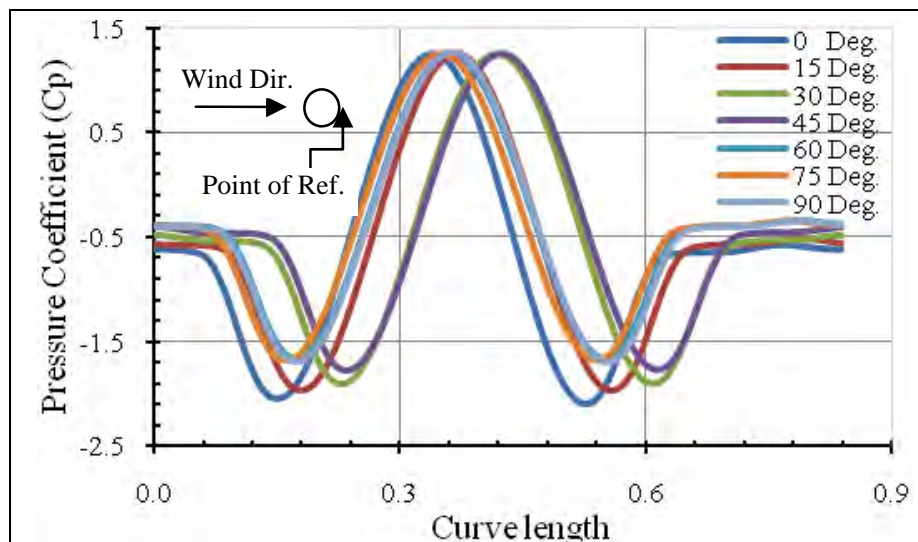

Figure 17: Pressure coefficient along the curve length of cooling tower 1 at level 6 using RNG $k-\varepsilon$ method

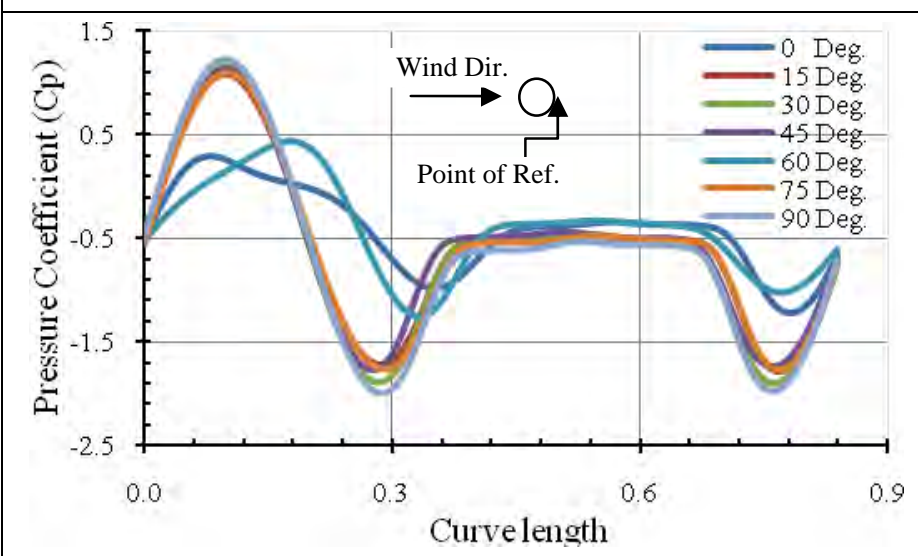

Figure 19: Pressure coefficient along the curve length of cooling tower 3 at level 6 using RNG $k-\varepsilon$ metho

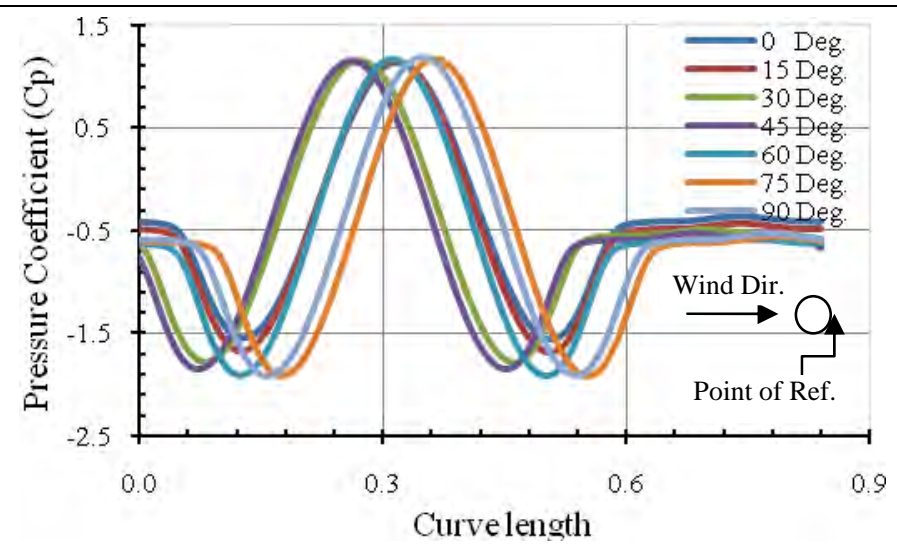

Figure 21: Pressure coefficient along the curve length of cooling tower 2 at level 6 using Realizable $k-\varepsilon$ method.

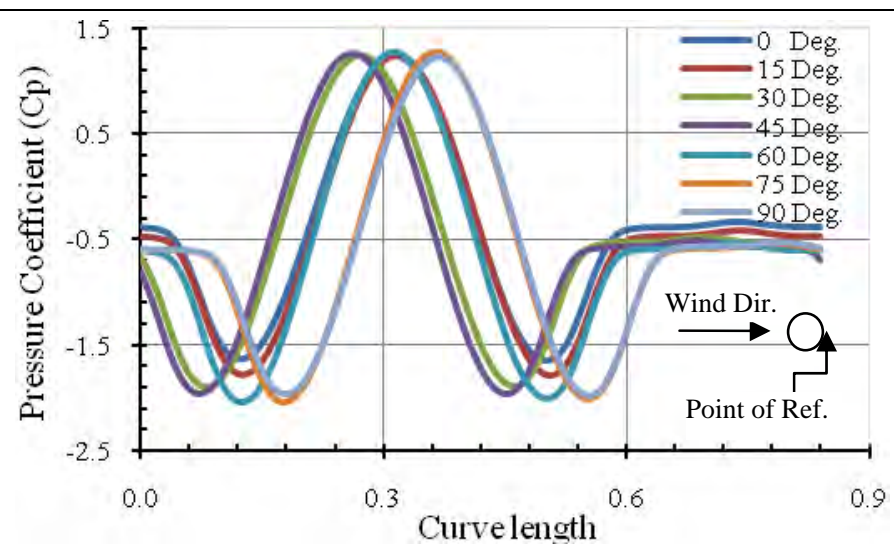

Figure 18: Pressure coefficient along the curve length of cooling tower 2 at level 6 using RNG $k-\varepsilon$ method

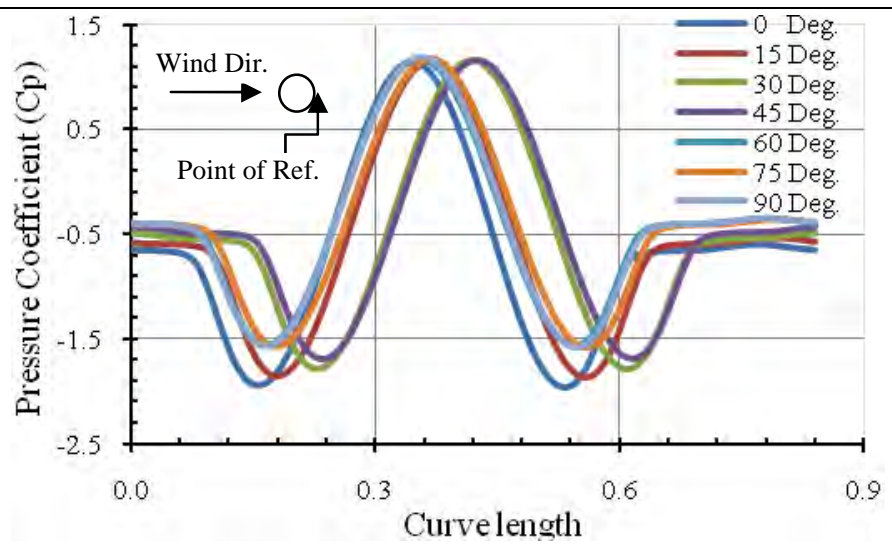

Figure 20: Pressure coefficient along the curve length of cooling tower 1 at level 6 using Realizable $k-\varepsilon$ method

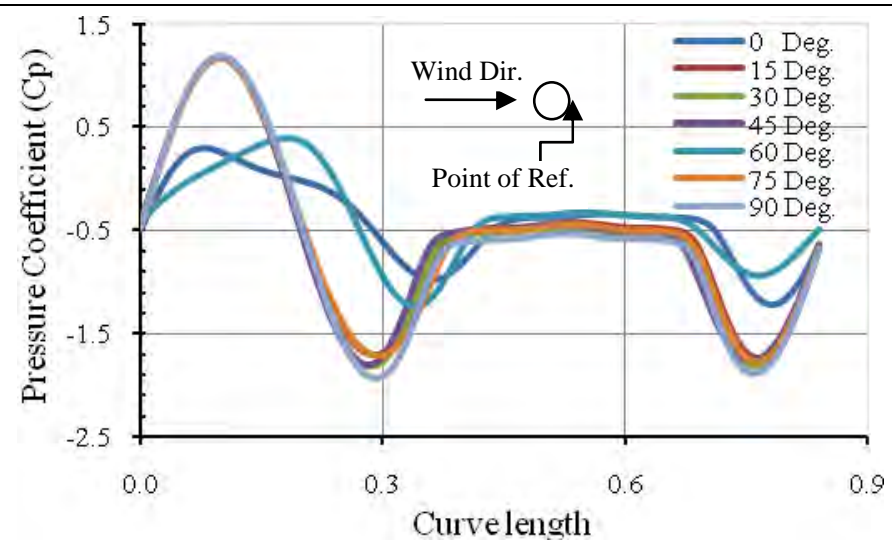

Figure 22: Pressure coefficient along the curve length of cooling tower 3 at level 6 using Realizable $k-\varepsilon$ method. 


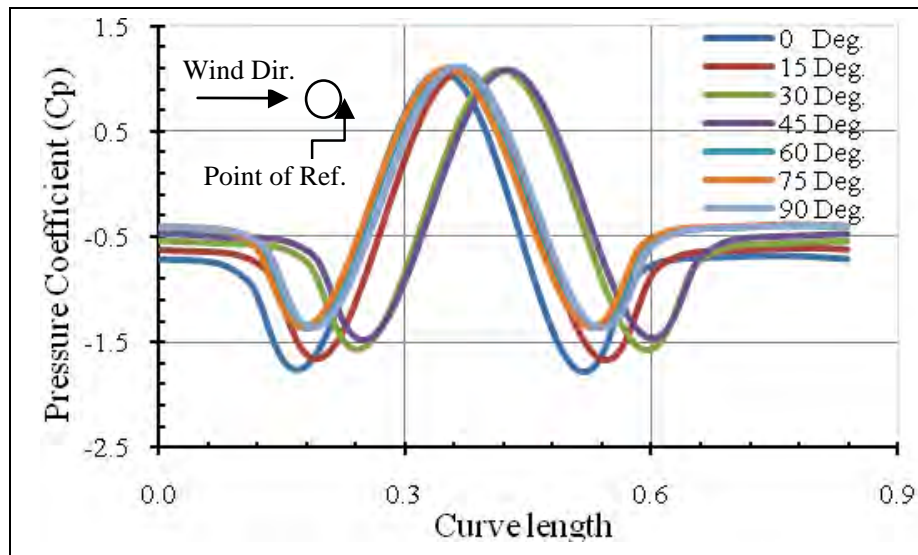

Figure 23: Pressure coefficient along the curve length of cooling tower 1 at level 6 using Reynolds stress method.

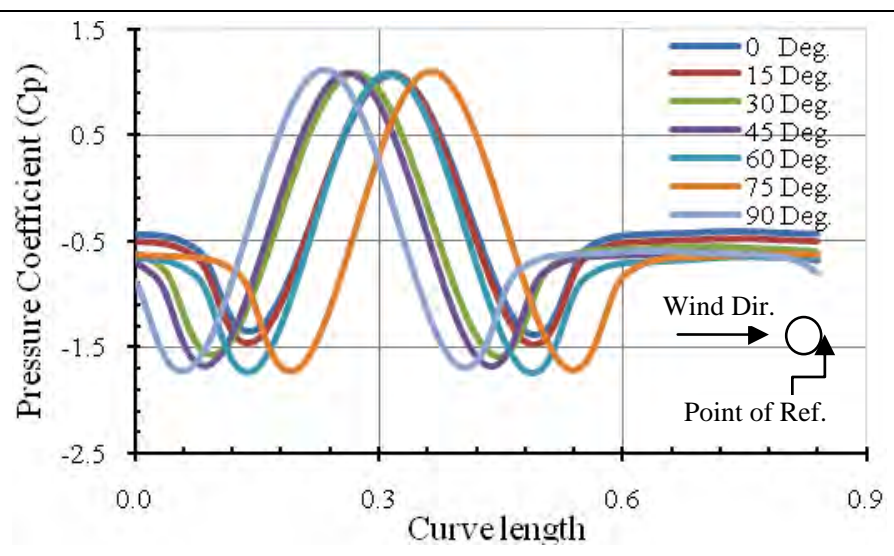

Figure 24: Pressure coefficient along the curve length of cooling tower 2 at level 6 using Reynolds stress method.

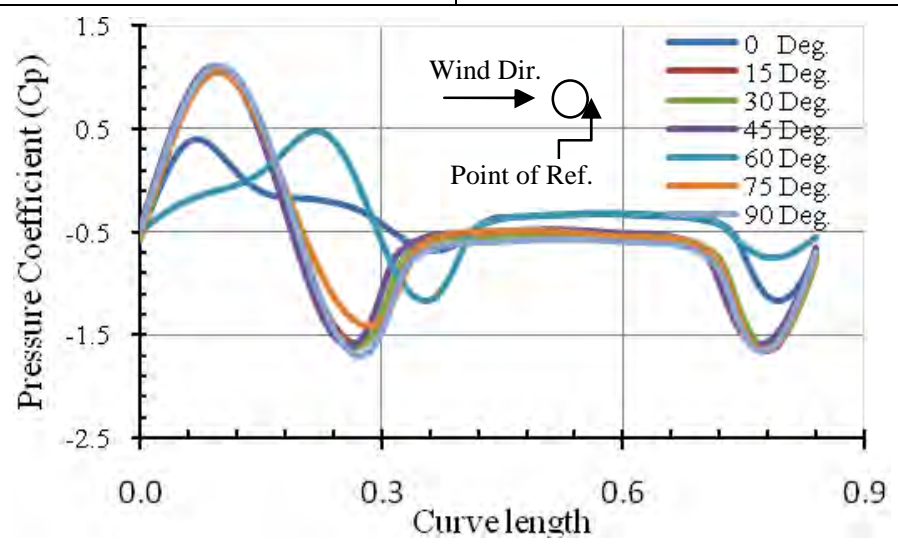

Figure 25: Pressure coefficient along the curve length of cooling tower 3 at level 6 using Reynolds stress method.

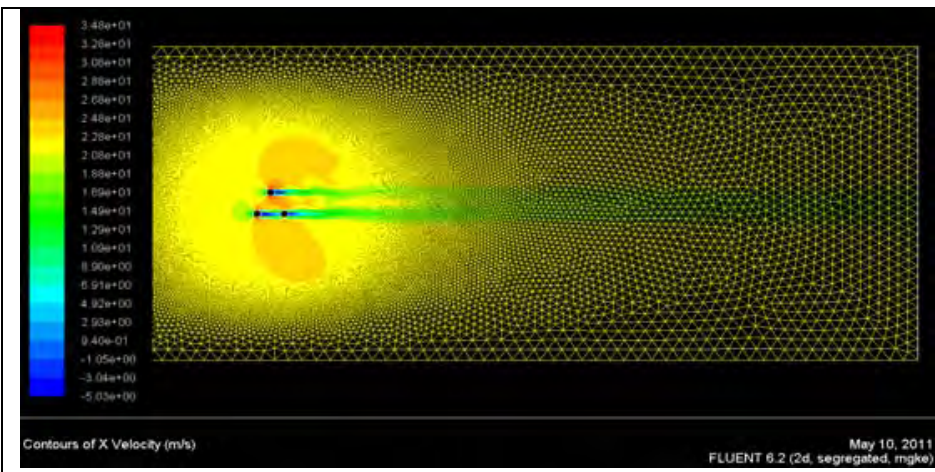

Figure 26: Velocity-contours of group of three cooling towers when wind incidence angle is $0^{\circ}$

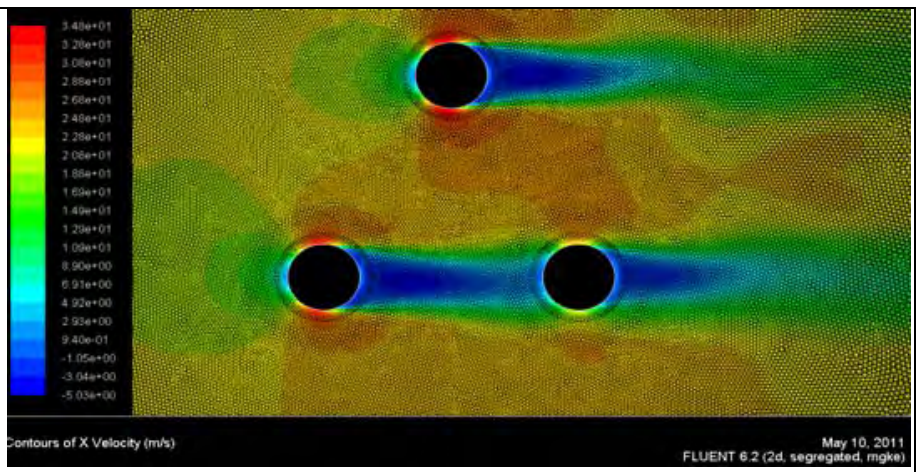

Figure 27: Enlarged view depicting interference at $0^{\circ}$ 


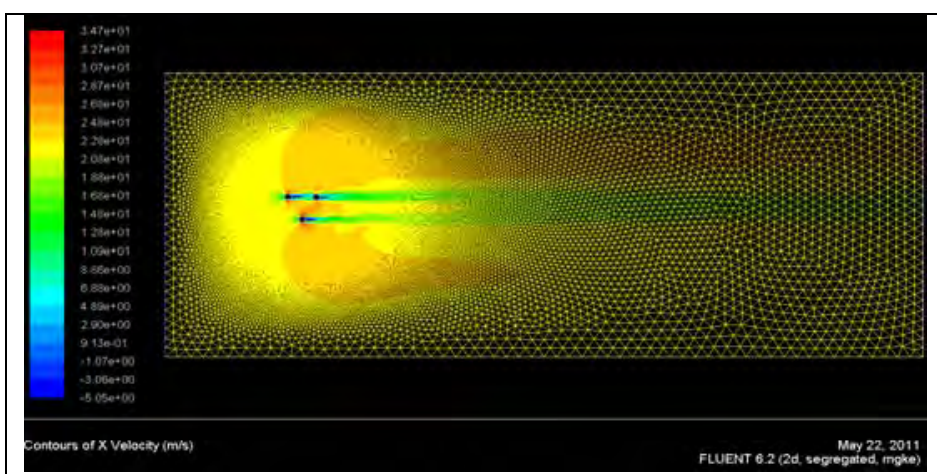

Figure 28: Velocity-contours of group of three cooling towers when wind incidence angle is $60^{\circ}$

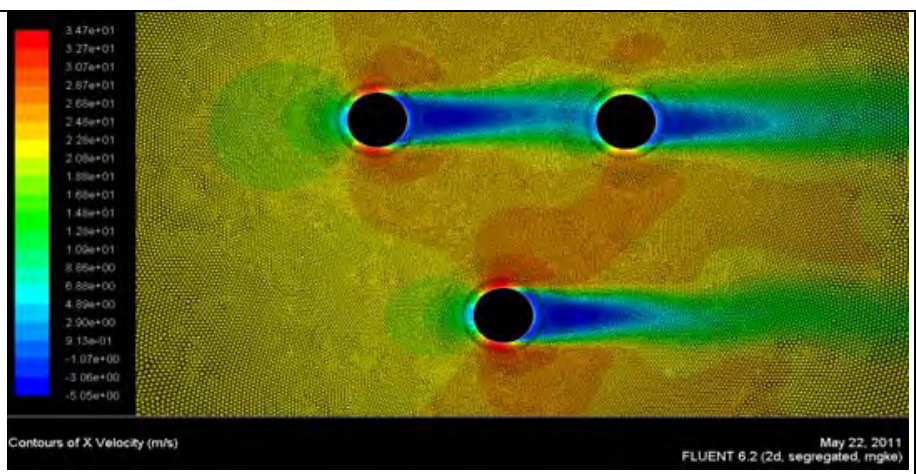

Figure 29: Enlarged view depicting interference at $60^{\circ}$

Similarly, for the combination of 5 cooling towers placed staggerly, the pressure coefficient values were plotted along its periphery on all the five cooling towers and the effect of interference were observed at different wind incidence angle as shown in Figures 30-44. From Figures 30, 33, 34, 35, 38, 39, 40, 43 and 44, it can be clearly seen that cooling tower 1, 4 and 5 were affected due to interference at wind incidence angle of $0^{\circ}$ and $60^{\circ}$ causing shielding effect on cooling tower 1,4 and 5 which led to the reduction of pressure coefficient values approximately by an amount of $50-80 \%$. The possible reason for this reduction is the formation of large wake or negative pressure region at windward face of cooling tower 1 due to presence of cooling tower 2 when the wind incidence angle is $0^{\circ}$ for cooling tower 1 , similarly due to the presence of cooling tower 3 when the wind incidence angle is $0^{\circ}$ for cooling tower 4 and 5 and due to the presence of cooling tower 1 and 2 when the wind incidence angle is $60^{\circ}$ for cooling tower 4 and 5 respectively. The Interference effects can also be clearly observed from x-velocity contours at different wind incidence angle as shown in Figures 45-48.

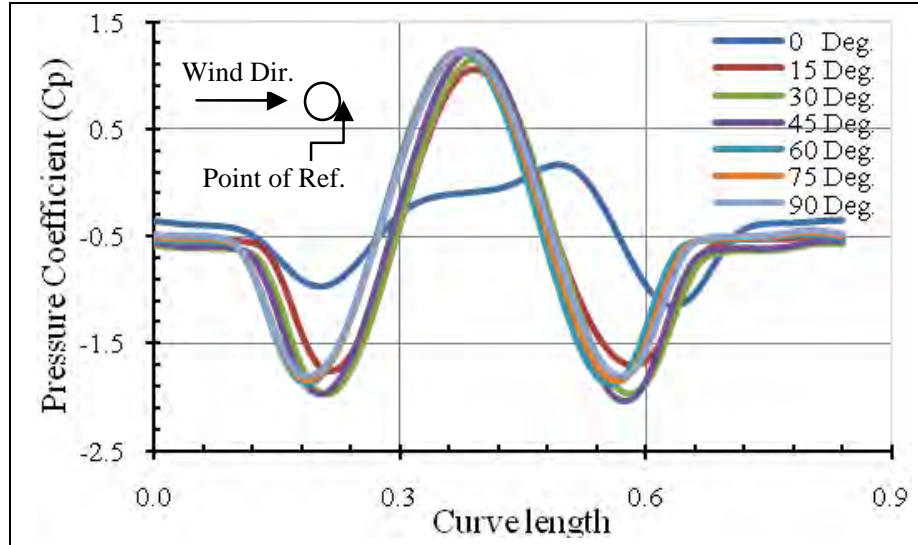

Figure 30: Pressure coefficient along the curve length of cooling tower 1 at level 6 using RNG $k-\varepsilon$ method

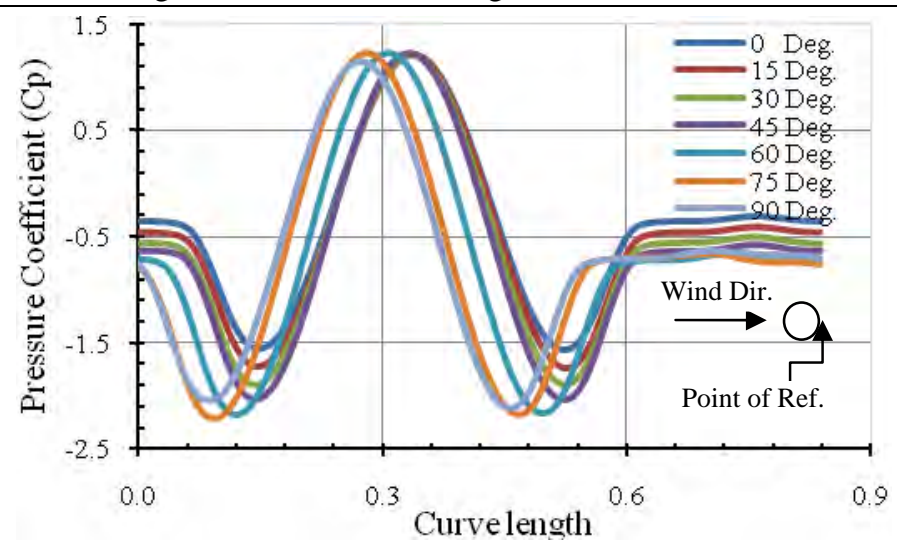

Figure 32: Pressure coefficient along the curve length of cooling tower 3 at level 6 using RNG $k-\varepsilon$ method

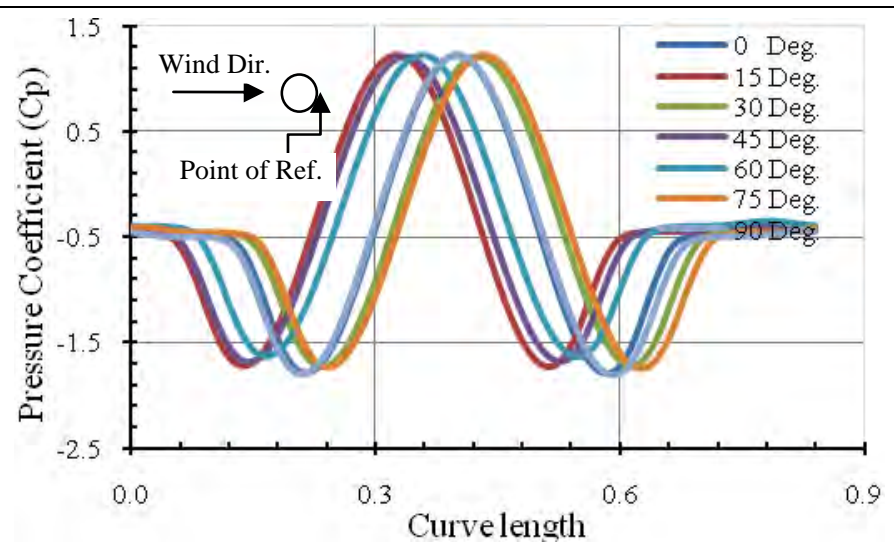

Figure 31: Pressure coefficient along the curve length of cooling tower 2 at level 6 using RNG $k-\varepsilon$ method

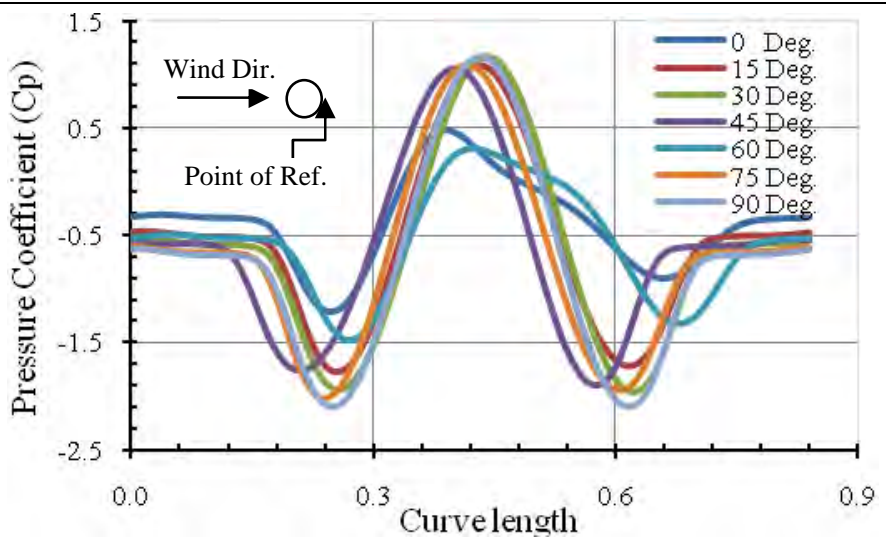

Figure 33: Pressure coefficient along the curve length of cooling tower 4 at level 6 using RNG $k-\varepsilon$ method 


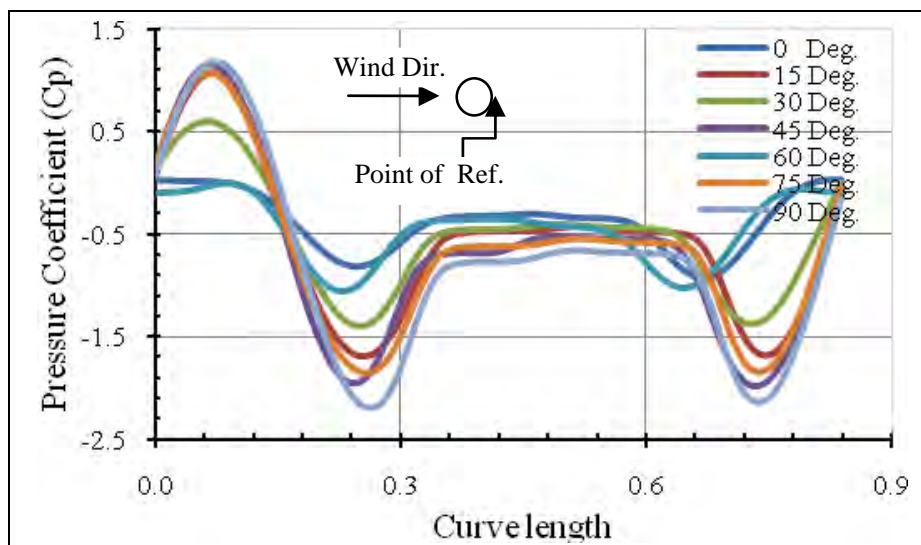

Figure 34: Pressure coefficient along the curve length of cooling tower 5 at level 6 using RNG $k-\varepsilon$ method

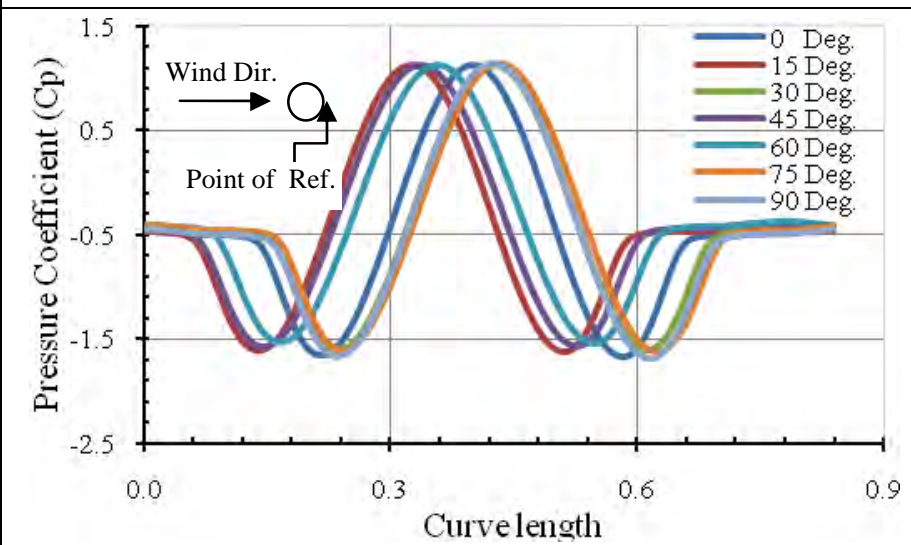

Figure 36: Pressure coefficient along the curve length of cooling tower 2 at level 6 using Realizable $k-\varepsilon$ method

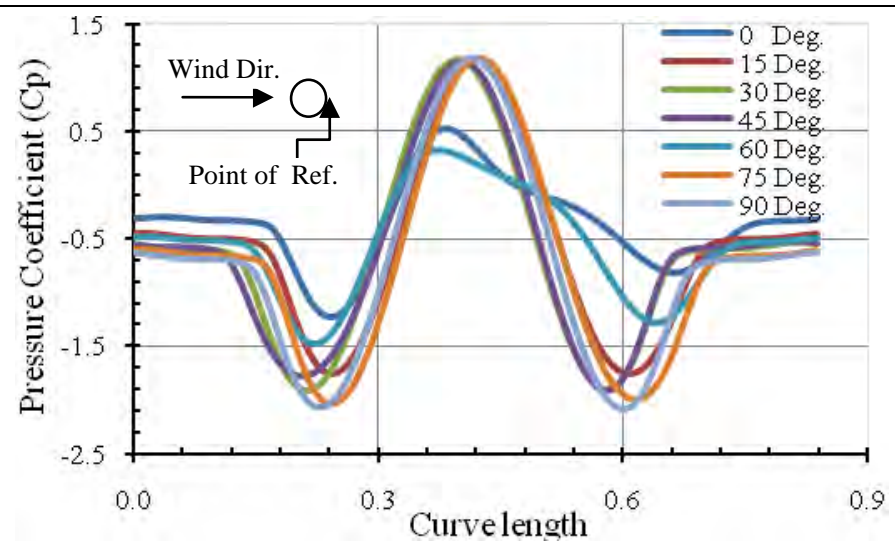

Figure 38: Pressure coefficient along the curve length of cooling tower 4 at level 6 using Realizable $k-\varepsilon$ method

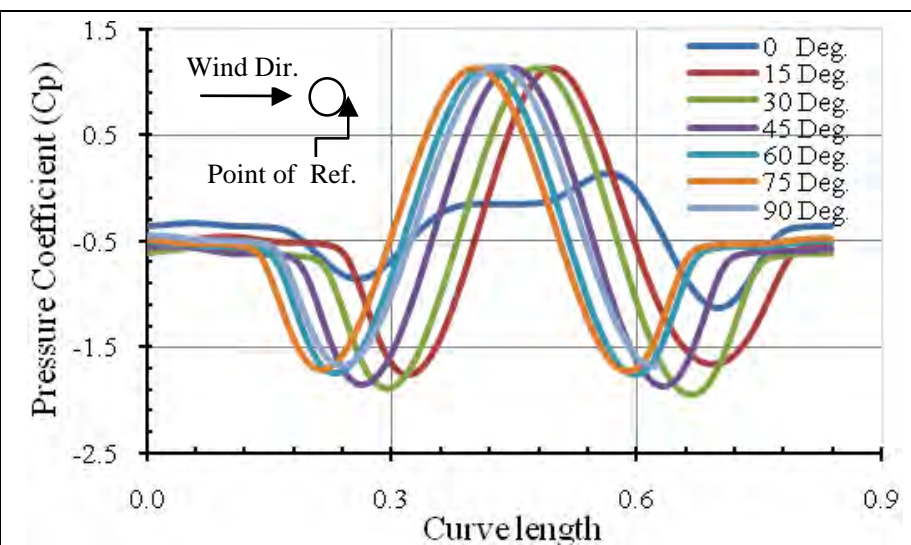

Figure 35: Pressure coefficient along the curve length of cooling tower 1 at level 6 using Realizable $k-\varepsilon$ method

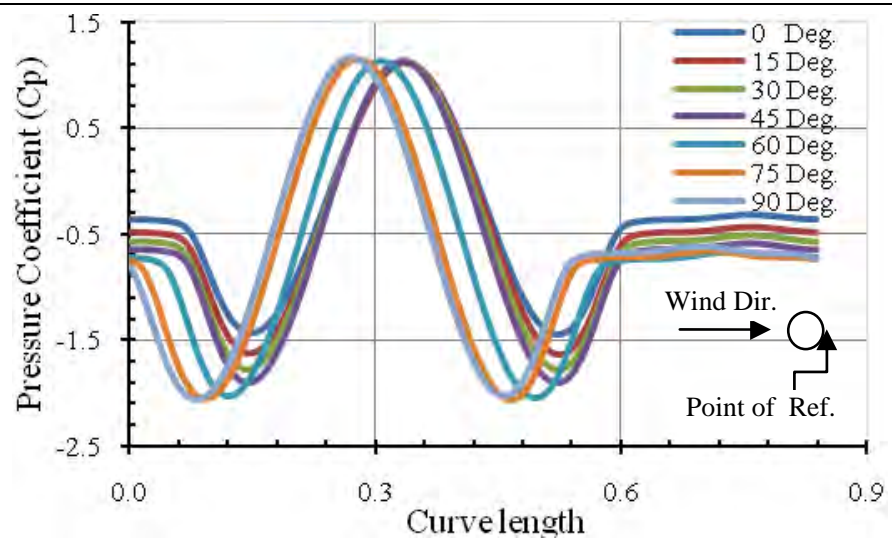

Figure 37: Pressure coefficient along the curve length of cooling tower 3 at level 6 using Realizable $k-\varepsilon$ method

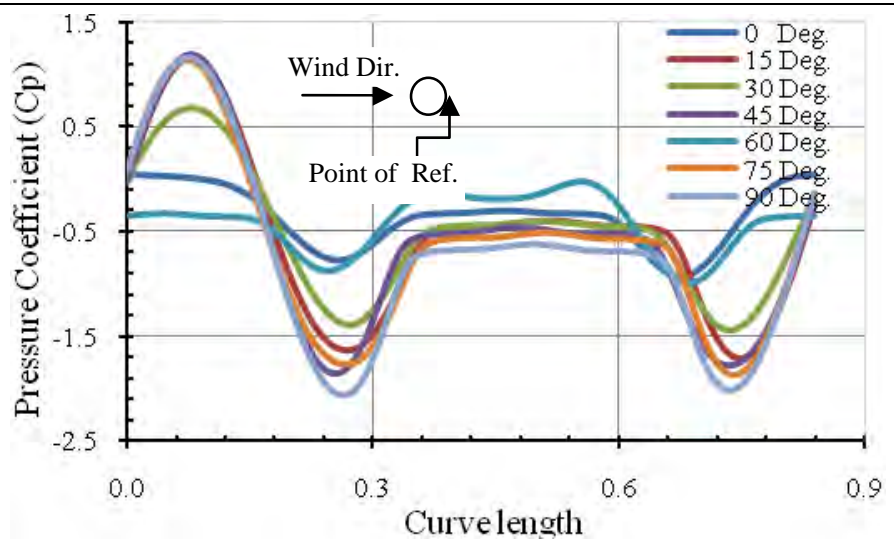

Figure 39: Pressure coefficient along the curve length of cooling tower 5 at level 6 using Realizable $k-\varepsilon$ method 


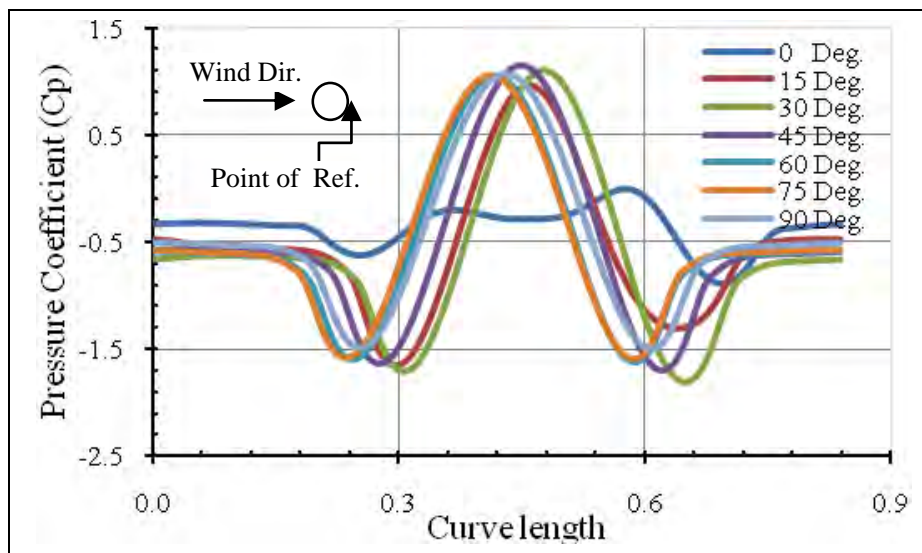

Figure 40: Pressure coefficient along the curve length of cooling tower 1 at level 6 using Reynolds stress method

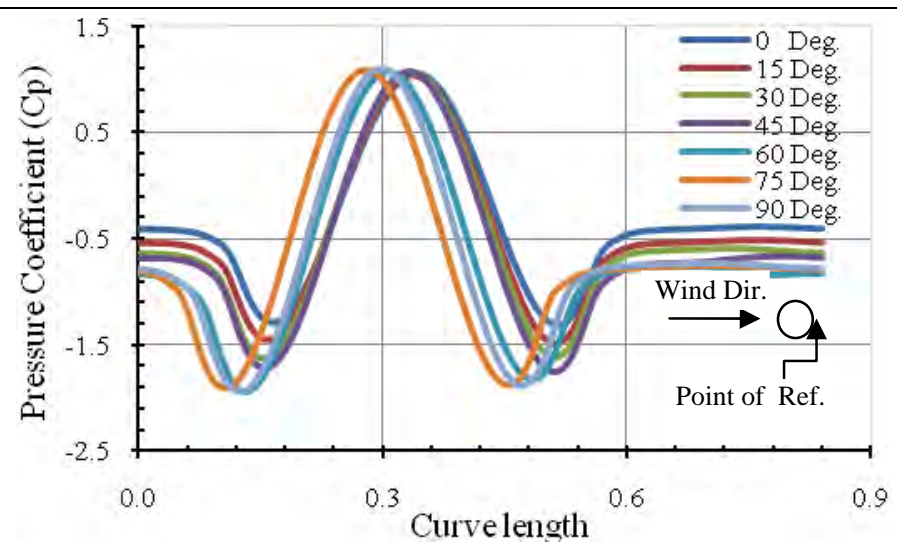

Figure 42: Pressure coefficient along the curve length of cooling tower 1 at level 6 using Reynolds stress method

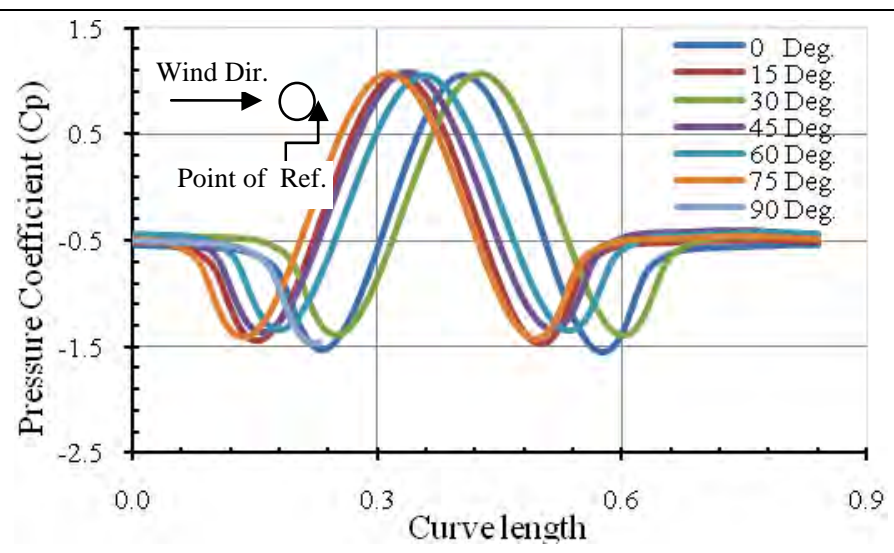

Figure 41: Pressure coefficient along the curve length of cooling tower 1 at level 6 using Reynolds stress method

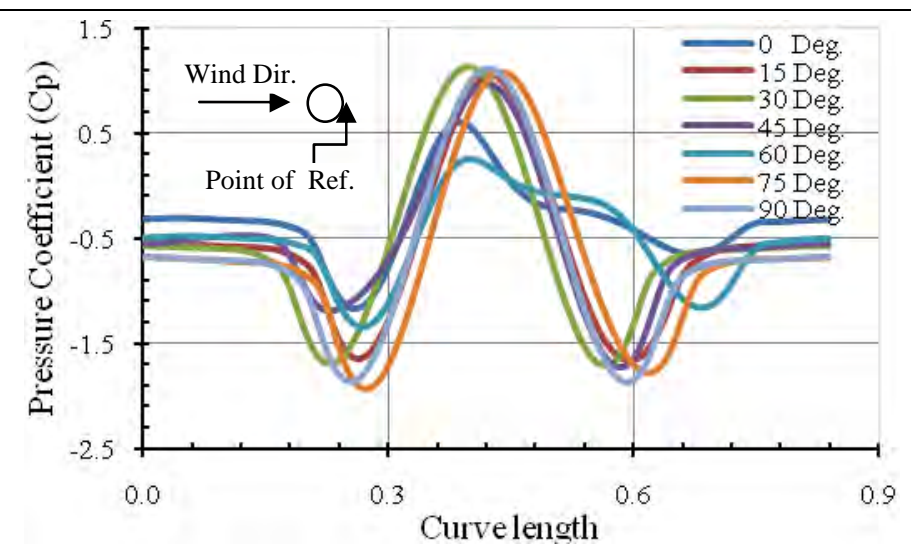

Figure 43: Pressure coefficient along the curve length of cooling tower 1 at level 6 using Reynolds stress method

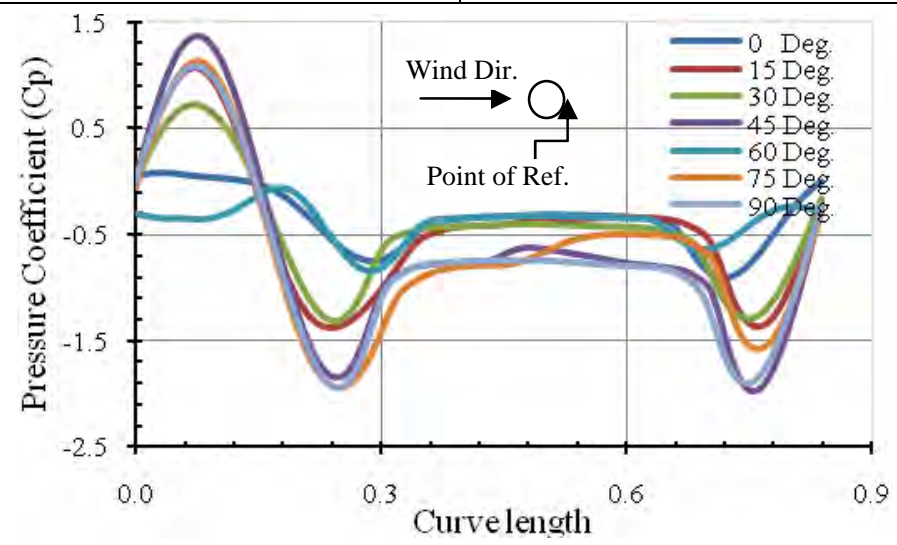

Figure 44: Pressure coefficient along the curve length of cooling tower 1 at level 6 using Reynolds stress method 


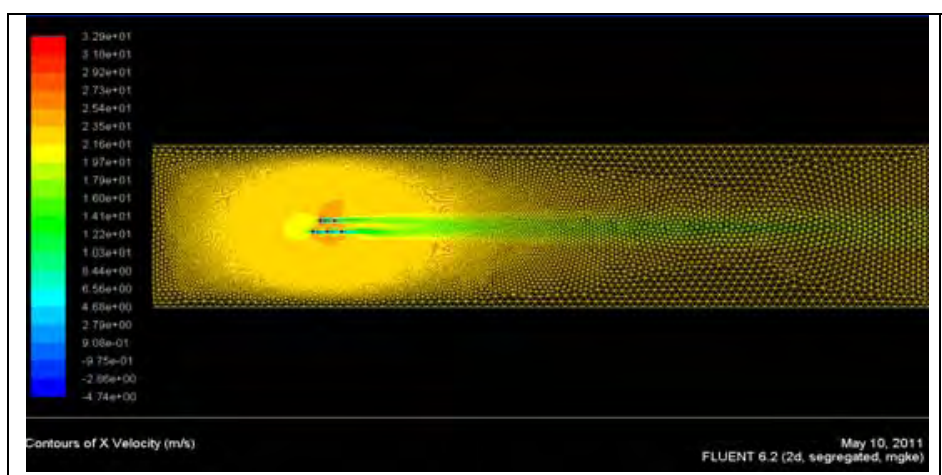

Figure 45: Velocity-contours of group of five cooling towers when wind incidence angle is $0^{\circ}$

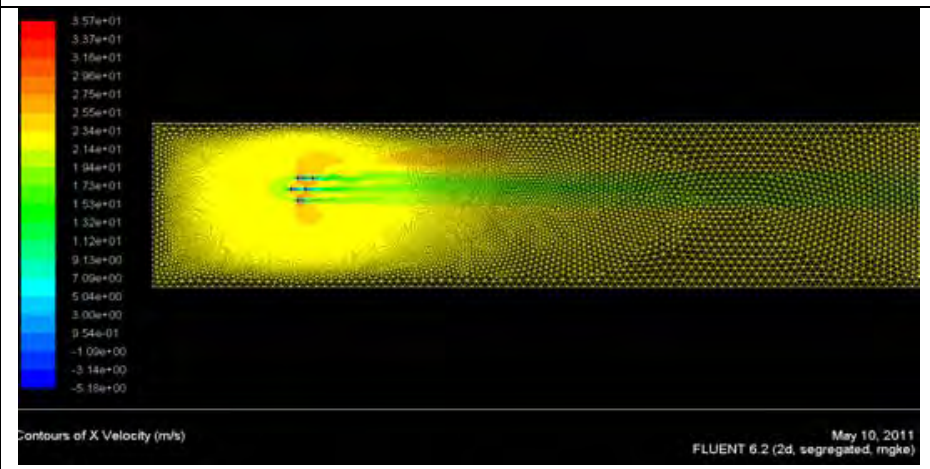

Figure 47: Velocity-contours of group of five cooling towers when wind incidence angle is $60^{\circ}$

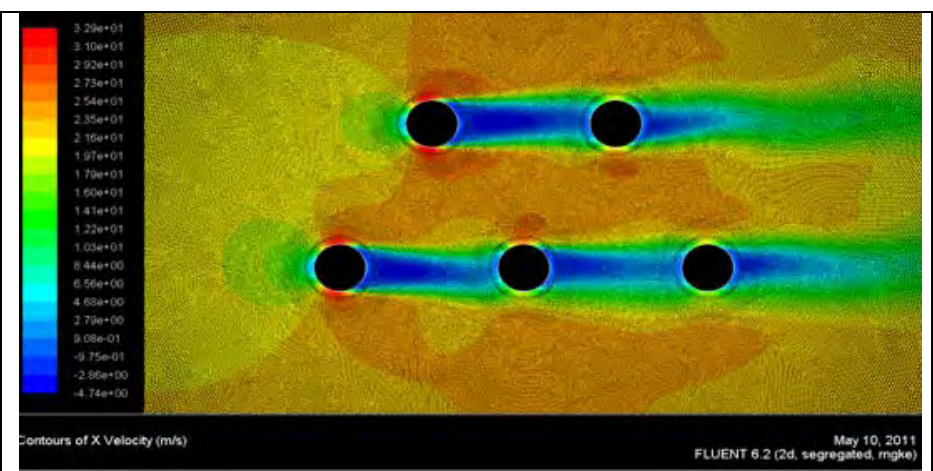

Figure 46: Enlarged view depicting interference at $0^{\circ}$

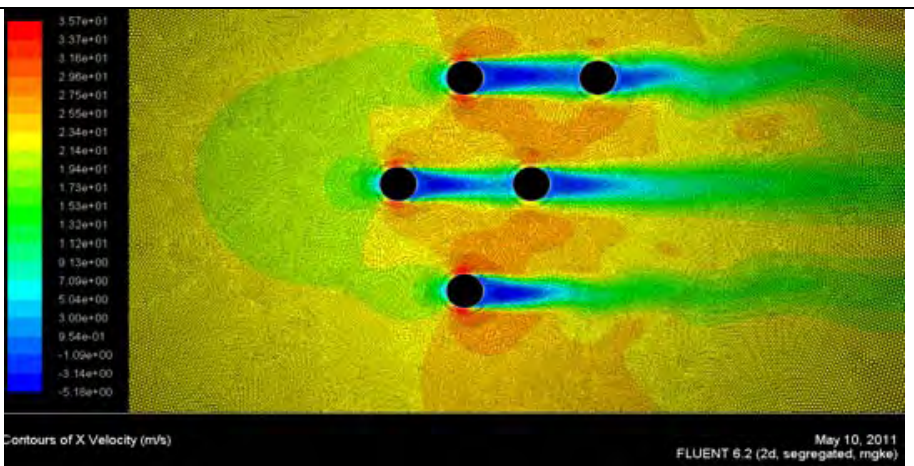

Figure 48: Enlarged view depicting interference at $60^{\circ}$

\subsection{Codal Provisons}

3.3.1 Recommendation of IS Code for pressure coefficient distribution: As per IS 11504-1985: 'Criteria for Structural Design of Reinforced Concrete Natural Draught Cooling Towers', the wind pressure distribution on the outside of the shell is assumed to be symmetrical about the centre line in the direction of wind. For practical design these values may be increased by 10 percent to take into account geometrical imperfections.

Table 3: Design wind pressure coefficient as per IS: 11504-1985 for the given wind incidence angle are tabulated below:

\begin{tabular}{|c|c|c|c|c|c|c|c|}
\hline $\begin{array}{c}\text { Angular posi- } \\
\text { tion measured } \\
\text { from the inci- } \\
\text { dent wind direc- } \\
\text { tion in degrees } \\
(\theta)\end{array}$ & $n$ values & $F_{n}$ & $\begin{array}{c}\text { Design wind } \\
\text { pressure coeffi- } \\
\text { cient } \\
P^{\prime}=\sum F_{n} \operatorname{Cosn} \theta\end{array}$ & $\begin{array}{c}\text { Design wind } \\
\text { pressure coeffi- } \\
\text { cient using } \\
\text { RNG } k-\varepsilon \\
\text { method for an } \\
\text { Isolated case }\end{array}$ & $\begin{array}{c}\text { \% error } \\
\text { w.r.t } \\
\text { IS code }\end{array}$ & $\begin{array}{c}\text { Design wind } \\
\text { pressure coeffi- } \\
\text { cient using } \\
\text { RNG } k-\varepsilon \text { me- } \\
\text { thod for single } \\
\text { interference case }\end{array}$ & $\begin{array}{c}\% \text { error } \\
\text { w.r.t. } \\
\text { isolated case }\end{array}$ \\
\hline 0 & 0 & -0.001 & 1.403 & 1.306 & 6.9 & 1.245 & 4.6 \\
15 & 1 & 0.246 & -0.032 & -0.011 & 63.8 & -0.013 & -16.2 \\
30 & 2 & 0.623 & -0.788 & -0.850 & -7.9 & -0.761 & 10.6 \\
45 & 3 & 0.488 & -0.717 & -0.639 & 11.0 & -0.758 & -18.7 \\
60 & 4 & 0.108 & 0.046 & 0.019 & 58.9 & 0.064 & -241.6 \\
75 & 5 & -0.096 & 0.843 & 0.793 & 6.0 & 0.756 & 4.6 \\
90 & 6 & -0.011 & 0.021 & 0.017 & 17.1 & 0.014 & 19.7 \\
\hline
\end{tabular}

From Table 3 above, it can be clearly observed for an isolated cooling tower, the maximum wind pressure coefficient as per IS 11504-1985 is 1.403 at $0^{\circ}$ incidence angle against the wind pressure coefficient value of 1.306 obtained using RNG $k-\varepsilon$ method. 
The percent reduction for the same was $6.9 \%$ with respect to IS code values. For an interference case of the cooling tower, the pressure coefficient value obtained at $0^{\circ}$ incidence angle was 1.245 . The percent reduction for the same was $4.6 \%$ with respect to isolated cooling tower. The maximum negative pressure coefficient of value -0.788 as per IS code was obtained at $30^{\circ}$ incidence angle against the pressure coefficient value of -0.850 obtained using RNG $k-\varepsilon$ method for an isolated cooling tower. The percent increase for the same was $7.9 \%$ with respect to IS code values. For an interference case the pressure coefficient value obtained at $30^{\circ}$ incidence angle was -0.761 . The percent reduction in maximum negative pressure coefficient value for the same was $10.6 \%$ with respect to isolated cooling tower.

\section{Results and Discussions}

In order to assess the relative abilities of the different turbulence models used to study the wind forces on the cooling tower, comparisons were made with the experimentally obtained data from the wind-tunnel tests conducted at IIT, Kanpur, India, for Krishnapatnam thermal power plant cooling tower in Andhra Pradesh, India. For this purpose a comparative study were carried out for an isolated and interfering cooling tower for different wind incidence angle. Different RANS techniques to model turbulence such as Standard $k-\varepsilon$ method, RNG $k-\varepsilon$ method, Realizable $k-\varepsilon$ method, and Reynolds stress method were used to verify the numerical results and its suitability with the wind-tunnel data. The obtained wind pressure coefficient values are plotted against the curve length (periphery) of the cooling towers using both experimental and numerical data.

4.1 Isolated case and Interference Case (single): For an isolated case of cooling tower, the standard $k-\varepsilon$ over predicted the wind pressure coefficient on the windward face by $20-25 \%$ at flow stagnation level. This may be due to the over production of turbulent kinetic energy. The remaining three CFD models predicted relatively similar results within approximately $10 \%$ of the experimentally obtained values on the wind-ward face. The result obtained using RNG $k-\varepsilon$ technique was in close proximity with the experimental results on the windward face only. On the leeward face, none of the CFD model corroborated the experimentally obtained results. However, the wind pressure coefficient on the leeward face of the cooling tower from the wind-tunnel experiments is close to zero over large range, which is not possible under any circumstances when incidence angle is $0^{\circ}$. This is due to the formation of large wake on the leeward face of the cooling tower.

Also on the side faces, none of the CFD model accurately predicted the experimentally obtained value. However, the integrity of every single CFD simulated model has been restored as they all predicted approximately similar pressure coefficient values. Besides this, there were a few inconsistent experimental points on the side faces that can be fully explained in lieu with analytical work carried out with the simulated of CFD model. The maximum pressure coefficient values obtained using RNG $k-\varepsilon$ method have decreased by a magnitude of nearly 7\% at zero degree wind incidence from the values obtained using IS 11504-1985 (Table 3). However, the maximum negative pressure coefficient values obtained using RNG $k-\varepsilon$ method have increased by a magnitude of nearly $8 \%$ at wind incidence angle of $30^{\circ}$, from the values obtained using IS 11504-1985 (Table 3).

The maximum wind pressure coefficient values obtained for single interfering case using RNG $k-\varepsilon$ method have decreased by a magnitude of $5 \%$ at wind incidence angle of $0^{\circ}$ from the values obtained using RNG $k-\varepsilon$ method for an isolated case (Table 3). However the maximum negative pressure coefficient values obtained using RNG $k-\varepsilon$ method have decreased by a magnitude of $11 \%$ at wind incidence angle of $30^{\circ}$, from the values obtained using RNG $k-\varepsilon$ method for an isolated case (Table 3).

4.2 Interference case (Three \& Five): In this study a group of three and five cooling towers placed staggerly were taken, in which simulation were carried out at different wind incidence angle from $0^{\circ}$ to $90^{\circ}$ at an interval of $15^{\circ}$ using RNG $k-\varepsilon$ method, Realizable $k-\varepsilon$ method, and Reynolds stress method. The standard $k-\varepsilon$ method was not considered because of the over production of turbulent kinetic energy on the windward face as seen for single and interfering cooling tower. The obtained pressure coefficient values were plotted along the curve length of each cooling tower.

In the case of three cooling towers it was evident from the Figure 17 to Figure 25 that when wind incidence angle was $0^{\circ}$ and $60^{\circ}$ with respect to cooling tower 2, cooling tower 3 was affected by both interference and shielding, whereas at the other remaining angles it was least affected. The maximum pressure coefficient values have decreased from 1.253 to 0.29 at $0^{\circ}$ incidence angle. The possible reason for this reduction was both shielding and interfering effects of cooling towers 1 and 2 on cooling tower 3 . However the maximum pressure coefficient values have decreased from 1.253 to 0.44 at wind incidence angle of $60^{\circ}$. The possible reason for this reduction was shielding effects of cooling tower 1 on cooling tower 3 . However, cooling tower 2 was mainly affected by the interference at wind incidence angle of $90^{\circ}$, whereas at the other remaining angles it was least affected. The maximum negative pressure coefficient values have increased from -1.635 to -1.978 at $90^{\circ}$ wind incidence angle. The possible reason for this reduction was interference effects of cooling towers 1 on cooling tower 2 .

In case of five cooling towers it was evident from Figure 30 to Figure 44 that when wind incidence angle was $0^{\circ}$ and $60^{\circ}$ with respect to cooling tower 3, cooling tower 1 and 4 were affected by interference, whereas at the other remaining angles it was least affected. The maximum pressure coefficient values for cooling tower 1 have decreased from 1.25 to 0.166 at $0^{\circ}$ incidence angle. The possible reason for this reduction was both shielding and interference effects of cooling towers 2, 3 and 4 on cooling tower 1 . Also the maximum pressure coefficient values at cooling tower 4 have decreased from 1.25 to 0.5 at wind incidence angle of $0^{\circ}$ (owing to shielding effect of cooling tower 3 on cooling tower 4) and from 1.25 to 0.3 at wind incidence angle of $60^{\circ}$ (owing to 
shielding and interference effect of cooling towers 2 and 3 on cooling tower 4). However cooling tower 5 was mainly affected at wind incidence angle of $0^{\circ}, 30^{\circ}, 60^{\circ}, 90^{\circ}$, whereas at the other remaining angles it was least affected. At $0^{\circ}, 30^{\circ}, 60^{\circ}$, the maximum negative pressure values have decreased considerably from -1.9 to -0.8 . But at $90^{\circ}$ incidence angle, an appreciable enhancement from -1.9 to -2.2 was observed in maximum negative pressure coefficient values. The possible reason for this reduction was interference effects of cooling towers 1,2 and 4 on cooling tower 5 .

However cooling tower 3 was mainly affected at $60^{\circ}$ and $75^{\circ}$ incidence angle. Both at $60^{\circ}$ and $75^{\circ}$ incidence angle, an appreciable enhancement from -2.0 to -2.2 were observed. The possible reason for this reduction was interference effects of cooling towers 2 and 4 on cooling tower 3.

\section{Conclusions}

Development work on the commercial CFD code has seen the successful implementation and testing of state of the art methods of modelling turbulence and flow filed. The availability of suitable techniques that will generate most precise solution is of utmost importance if it has to be accepted as an alternative to wind-tunnel testing, which in turn economizes the analysis and design of structures. The extensive work done suggests that the anisotropy of turbulent flow for wind engineering can be suitably modelled using various RANS techniques, however, among all the techniques used so far RNG $k-\varepsilon$ turbulent model is found to be in close proximity with the wind-tunnel data on the windward face for all the case studied. The numerical data and wind-tunnel data on the leeward face of the cooling tower is not showing any resemblance for all the RANS techniques used. This suggests the eventual need to reduce the importance of the turbulence model and the necessity to resolve more of the flow field directly i.e. large eddy simulation. The large eddy simulation requires significant computer facilities.

For isolated cooling tower the maximum positive and negative pressure coefficient on the windward and leeward face by windtunnel and RNG $k-\varepsilon$ turbulent model are 1.314, -0.788 and 1.306, -1.808 respectively. Thus, the numerical data and wind-tunnel data on the leeward face of the cooling tower is not showing any resemblance, however on the windward face the pressure coefficients are nearly same. The wind-tunnel data show nearly zero pressure coefficient over long range seems not possible as large wake is forming on the leeward face of the cooling tower. The net pressure coefficient for the isolated case agrees well within the data given in BS 4998: Part 1: 1992 and IS: $11504-1985$ for maximum value of Cp $(=1.403)$. The minimum value of Cp (= 0.788) is well within (in terms of magnitude) the value (-0.95) given in IS Code. The magnitude of this minimum Cp is well within the current design practice.

In case of multiple cooling towers, both shielding and interfering effect has been observed, which led to either reduction or enhancement in wind pressure coefficient values at different wind incidence angle. Shielding do not increase the positive wind pressure but because of interference and shielding effect both, remarkable increase in suction has been observed because of large wake on the leeward face of the cooling towers. Because of interference and shielding effect the negative pressure sometimes have been found to increase by more than 33\% to that of the isolated cooling tower. Therefore, it is necessary to thoroughly investigate the pressure coefficient on all the cooling towers in group individually at all angle of incidence before designing the towers.

\section{Nomenclature}

$\begin{array}{ll}\text { ANN } & \text { Artificial neural network } \\ \text { B } & \text { Total dimension along the length of the cooling towers } \\ \text { CAARC } & \text { Commonwealth advisory aeronautical council } \\ \text { CFD } & \text { Computational fluid dynamics } \\ \text { CWE } & \text { Computational wind engineering } \\ \text { D } & \text { Total dimension along the width of the cooling towers } \\ \text { DNS } & \text { Direct numerical simulation } \\ \text { IIT } & \text { Indian Institute of Technology } \\ \text { IITK } & \text { Indian Institute of Technology, Kanpur } \\ \text { LES } & \text { Large eddy simulation } \\ \text { NDCT } & \text { Natural drought cooling tower } \\ \text { RANS } & \text { Reynolds averaged Navier-Stokes } \\ \text { Re } & \text { Reynolds number } \\ \text { RKE } & \text { Realizable } k-\varepsilon \\ \text { RNG } & \text { Renormalization group } \\ \text { RNGKE } & \text { Renormalization group } k-\varepsilon \\ \text { RSM } & \text { Reynolds stress method } \\ \text { SKE } & \text { Standard } k-\varepsilon \\ \text { T1, T2, } \ldots & \text { Cooling tower number } \\ 2 D & \text { Two dimensional } \\ k & \text { Turbulent kinetic energy } \\ \varepsilon & \text { The dissipation of turbulent kinetic energy }\end{array}$




$\begin{array}{ll}\rho & \text { Density of air } \\ u_{\tau} & \text { Ground shear stress } \\ \mu & \text { Kinematic viscosity of air } \\ y & \text { Distance from the wall to the centre of first cell. }\end{array}$

\section{References}

Babu T. M., Khan K., Nema M.K., Raghavan N. 2004. 'A comparative study of wind dynamic effects on NDCTs as per various international standards', Proceedings of the Fifth International Symposium on Natural Drought Cooling Towers, 20-22 May, Istanbul, Turkey.

Blocken B., Carmeliet J., Stathopoulos T. 2007. 'CFD evaluation of wind speed conditions in passages between parallel buildings - effect of wall-function roughness modifications for the boundary layer flow', Journal of Wind Engineering and In dustrial Aerodynamics, Vol. 95, No. 9-11, pp. 941-962.

Easom G. 2000 'Improved turbulence models for computational wind engineering', PhD thesis, University of Nottingham, U.K.

Gloria M. Gomes et al., 2004. 'Experimental and numerical study of wind pressures on irregular-plan shapes, Journal of Wind En gineering and Industrial Aerodynamics, Vol. 93, No. 10, pp. 741-756.

Grebik V., Spirek K. 2004. 'REKO PRAHA scaffolding and formwork for Itterson cooling tower', Proceedings of the Fifth In ter national Symposium on Natural Drought Cooling Towers, 20-22 May 2004, Istanbul, Turkey.

Horr A.M., Asadsajadi S.R., Safi M. 2004. 'Design of concrete cooling tower structures with imperfection using ANN-based simu lator', Proceedings of the Fifth International Symposium on Natural Drought Cooling Towers, 20-22 May, Istanbul, Turkey.

Huang S., Li Q.S. and Xu S. 2007. 'Numerical evaluation of wind effects on tall steel building by CFD', Journal of Construction Steel Research, Vol. 63, No. 5, pp. 612-627.

Heggade V.N. 2004. 'Evolution of analysis and modeling of NDCTs in India', Proceedings of the Fifth International Symposium on Natural Drought Cooling Towers, 20-22 May, Istanbul, Turkey.

Irtaza H., Beale R.G., Godley M.H.R. 2009a. 'Wind Loads on Netted Metal Access Scaffolds', Proceedings of Sixth Interna tional Conference on Advances in Steel Structures, 16-18 December 2009, pp. 1091-1098, Hong Kong, China.

Irtaza H., Beale R.G., Godley M.H.R. 2009b. 'Experimental and numerical evaluation by CFD of wind loads on sheeted scaffolds', Proceedings of the $12^{\text {th }}$ International Conference on Civil, Structural and Environmental Engineering Computing, Madeira Island, Portugal, September 1-4, 2009.

IS: 4998: Part 1:1992. 'Criteria for Design of Reinforced Concrete Chimneys, Part 1: Assessment of Loads', Bureau of Indian Standards, New Delhi.

IS: 11504 -1985. 'Criteria for Structural Design of Reinforced Concrete Natural Drought Cooling Towers' Bureau of Indian Standards, New Delhi.

Li Q.S., Melbourne W.H. 1995. 'An experimental investigation of the effects of free-stream turbulence on streamwise surface pressures in separated and reattaching flows, Journal of Wind Engineering and Industrial Aerodynamics, Vol. 51-52, pp.313-23.

Li Q.S., Melbourne W.H. 1999. 'Turbulence effects on surface pressures of rectangular cylinders', An International Journal of Wind and Structures, Vol. 83, pp. 159-69.

Montag U., Busch D., Harte R., Kratzig W.R. 2004. 'The 200m Niederaussem tower-design and static approach', Proceedings of the Fifth International Symposium on Natural Drought Cooling Towers, 20-22 May, Istanbul, Turkey.

Min C.S. 2004. 'Design and ultimate behaviour of cooling tower', Evolution of analysis and modeling of NDCTs in India', Pro ceedings of the Fifth International Symposium on Natural Drought Cooling Towers, 20-22 May 2004, Istanbul, Turkey.

Murakami S. 1997. 'Overview of turbulence models applied in CWE', Institute of Industrial Science, University of Tokyo, Japan.

Murakami S. 1998. 'Overview of turbulence models applied in CWE-1997', Journal of Wind Engineering and Industrial Aerody namics, Vol. 74-76, pp.1-24.

Rajeshirke U.K., Upendra Nath B.N., Kulkarni N.N., Alimchandani C.R. 2004. 'Natural draught cooling towers in India', Proceed ings of the Fifth International Symposium on Natural Drought Cooling Towers, 20-22 May 2004, Istanbul, Turkey.

Report on wind-tunnel study of NDCT for $2 \times 800 \mathrm{mw}$ thermal power project carried out by National Wind Tunnel Facility, Indian Institute of Technology Kanpur, 2010.

Wright N.G. and Easom G.J. 2003. 'Non-Linear $k-\varepsilon$ Turbulence Model Results for Flow over a Building at Full-Scale', Applied Ma-thematical Modelling, Vol. 27, No. 12, pp. 1013-1033.

\section{Biographical notes}

Dr. Hassan Irtaza, Associate Professor, Department of Civil Engineering, Aligarh Muslim University, Aligarh, India. Ph. D Awarded from Oxford Brookes University, Oxford, U.K. in the area of Wind Engineering and Computational Fluid Dynamics and having teaching and research experience of more than sixteen years. Areas of research are Wind engineering, Earthquake engineering and structural dynamics 
Dr. Shakeel Ahmad, Professor, Department of Civil Engineering, Aligarh Muslim University, Aligarh, India. Ph. D Awarded from Indian Institute of Technology, Roorkee in the area of Wind Engineering and having teaching and research experience of more than twenty five years. Areas of research are Wind engineering, Earthquake engineering and structural dynamics

Mr. Tarun Pandey, Post graduate student, Department of Civil Engineering, Aligarh Muslim University, Aligarh, India.

Received June 2011

Accepted October 2011

Final acceptance in revised form November 2011 